\title{
El trato justo y equitativo en los tratados de protección recíproca de inversiones ecuatorianos
}

\author{
Camilo Muriel Bedoya* \\ Recibido/Received: 27/06/2017 \\ Aceptado/Accepted: 21/07/2017
}

\begin{abstract}
SUMARIO: 1. Introducción. 2. Trato justo y equitativo y el estándar mínimo internacional. 2.1 El estándar mínimo internacional y su relación con el TJE. 2.2 Contenido del TJE. 2.3 Contenido del estándar mínimo internacional: administración de justicia y protección de propiedad. 2.4 Estándar moderno y protección de propiedad. 3. El trato justo y equitativo en los tratados bilaterales de inversión ecuatorianos y su tratamiento por los tribunales arbitrales de inversión. 3.1 El trato justo y equitativo en los TBIs ecuatorianos. 3.2 Particularidades del TJE en los TBIs ecuatorianos. 3.3 Aplicación del derecho internacional y cláusulas de nación más favorecida. 4. El TJE en los arbitrajes de inversión ecuatorianos y la postura de la Procuraduría General del Estado y de la CAITISA. 4.1 EnCana Corporation c. Ecuador. 4.2 Occidental Exploration c. Ecuador (Occidental I). 4.3 Occidental Exploration c. Ecuador (Occidental II). 4.4 Duke Energy c. Ecuador. 4.5 M.C.I. c. Ecuador. 4.6 Murphy Exploration c. Ecuador (Murphy II). 4.7 Perenco Ecuador Limited c. Ecuador. 4.8 Postura de la Procuraduría General del Estado. 4.9 Postura de la CAITISA y denuncia de los TBIs. 5. Conclusión.
\end{abstract}

\footnotetext{
Asociado en Pérez Bustamante \& Ponce Abogados. Abogado y Licenciado en Ciencias Jurídicas por la Pontificia Universidad Católica del Ecuador, LL.M., por la University College London y Especialista Superior en Derecho de la Empresa por la Universidad Andina Simón Bolívar.

C. Muriel Bedoya, "El trato justo y equitativo en los tratados de protección recíproca de inversiones ecuatorianos", Revista Ecuatoriana de Arbitraje, No. 8, 2016.
} 
PALABRAS CLAVE: Ecuador, inversión extranjera, trato justo y equitativo, TJE, tratado bilateral de inversión, TBI, arbitraje de inversión.

KEYWORDS: Ecuador, foreign investment, fair and equitable treatment, FET, bilateral investment treaty, BIT, investment arbitration.

RESUMEN: El trato justo y equitativo es uno de los estándares más importantes en el derecho internacional de la inversión extranjera y quizás sea el más invocado en las disputas Inversionista-Estado. Su importancia, sin embargo, es inversamente proporcional a la definición de su contenido. Este artículo analiza al trato justo y equitativo, su relación con el estándar mínimo internacional, cómo ha sido recogido en los principales instrumentos bilaterales de inversión ecuatorianos, cómo lo han abordado diferentes tribunales arbitrales de inversión en los cuales Ecuador ha sido parte, y cuál es la postura de la Procuraduría General del Estado y de la CAITISA. Se concluirá que el estándar está expresamente reconocido por la República del Ecuador, que su contenido y alcance se encuentran en constante desarrollo y que una definición estricta y exhaustiva, sin embargo, podría no ser lo más recomendable para su evolución.

ABSTRACT: Fair and equitable treatment is one of the most important standards in international law of foreign investment and it is probably the most invoked standard in Investor-State disputes. Its importance, however, is inversely proportional to the definition of its content. This article analyses the fair and equitable treatment standard, its relationship with the international minimum standard, how it has been established in the main Ecuadorians bilateral investment treaties, the approach taken by different investment arbitral tribunals where Ecuador has been a party, as well as the position of the Ecuadorian Attorney General Office and CAITISA. It will be concluded that the Republic of Ecuador expressly recognises the standard, that its content and scope 
are in constant development and that a strict and exhaustive definition, however, might not be the best for its evolution.

\section{INTRODUCCIÓN}

Uno de los estándares y obligaciones más importantes del derecho internacional de inversiones es el trato justo y equitativo. Se afirma que es el estándar con la mayor relevancia práctica en arbitrajes de inversión ${ }^{1}$, la obligación que más probablemente sea encontrada como violada en estos arbitrajes ${ }^{2}$, y que quizás sea la más importante obligación impuesta a los Estados por medio de instrumentos internacionales ${ }^{3}$. El sistema descentralizado de resolución de controversias relativas a inversiones poco a poco ha ido identificando los elementos que forman parte del estándar, pero no existe todavía un consenso respecto a su naturaleza, definición y alcance. La discusión está lejos de terminar, sin embargo, es síntoma de que el estándar se encuentra en constante desarrollo.

Este trabajo abordará el estudio del trato justo y equitativo en el derecho internacional de inversiones, cómo se encuentra reflejado en los instrumentos internacionales de protección recíproca de inversiones suscritos por el Ecuador, y su aplicación. Se partirá de su relación con el derecho consuetudinario internacional para identificar sus fuentes y contenido. Así, en la primera parte se repasará el origen del trato justo y equitativo, su vínculo con el estándar mínimo internacional, y cómo ha tomado forma en la práctica, particularmente en tratados bilaterales de inversión.

1. R. Dolzer y C. Schreuer, Principles of International Investment Law, 2da. Ed., Oxford University Press, 2012, p. 130.

2. M. PAPARINSKIS, The International Minimum Standard and Fair and Equitable Treatment, Oxford University Press, 2013, p. xlxxx.

3. F. ORTINO, "Fair and Equitable Treatment in Investment Treaty Law", en F. OrTINO (Ed.), et al, Investment Treaty Law. Current Issues II: Nationality and investment treaty claims. Fair and equitable treatment in investment treaty law, British Institute of International and Comparative Law, Londres 2007, p. 90 . 
Posteriormente, en la segunda parte, se identificará cómo se ha cristalizado el trato justo y equitativo en los instrumentos internacionales de protección recíproca de inversiones suscritos por el Ecuador. Específicamente, se revisarán los tratados bilaterales de inversión suscritos con Alemania, Argentina, Bolivia, Canadá, Chile, China, Estados Unidos, Finlandia, Francia, Italia, Países Bajos, Perú, España, Suecia, Suiza, Reino Unido, y Venezuela. Finalmente, se revisará qué han señalado tribunales de inversión respecto al trato justo y equitativo en los casos más relevantes en los que Ecuador ha sido parte, la posición de la Procuraduría General del Estado y de la CAITISA ${ }^{4}$, y los futuros desafíos para el Ecuador con la denuncia de los TBIs.

\section{TRATO JUSTO Y EQUITATIVO Y EL ESTÁNDAR MÍNIMO INTERNACIONAL}

DOLZER y SCHREUER sugieren que el trato justo y equitativo $(\mathrm{TJE})^{5}$ tiene sus orígenes en los Tratados de Amistad, Comercio y Navegación. Afirman que su propósito es llenar los vacíos que pueden dejar otros estándares -particularmente en acuerdos bilaterales o multilaterales de protección recíproca de inversionespara alcanzar un nivel mínimo de protección a la inversión extranjera ${ }^{6}$ y que, para determinar su concepto, es necesario identificar las situaciones a las que comúnmente se lo ha aplicado ${ }^{7}$. Así, entran en juego varios principios -como por ejemplo, transparencia, debido proceso, y buena fe- que han sido incorporados y desarrollados por el TJE. Su ámbito, sin embargo, está en continuo desarrollo y al parecer otros elementos se han ido sumando, como es el caso de la protección de las expectativas legítimas de un inversionista.

4. La Comisión para la Auditoría Integral Ciudadana de los Tratados de Protección Recíproca de Inversiones y del Sistema de Arbitraje Internacional en Materia de Inversiones (CAITISA) fue creada mediante Decreto Ejecutivo No. 1506, de 6 de mayo de 2013, con el objeto de realizar una revisión de los TBIs ecuatorianos y del sistema de arbitraje de inversiones.

5. Es común que se lo refiera también como "FET", por sus siglas en inglés (Fair and Equitable Treatment).

6. R. Dolzer y C. Schreuer, N. 1, pp. 120-122.

7. Ídem, p. 145 . 
La cuestión principal, entonces, es determinar cómo y de qué forma se manifiesta el TJE como una obligación de un Estado. Por ejemplo, en el caso de las expectativas legítimas de los inversionistas, la pregunta que surge es cómo y hasta qué punto la conducta y representaciones de un gobierno pueden darlas a lugar. Estas podrían basarse en las condiciones existentes previas a la inversión y que un Estado podría estar obligado a mantener, pero dependerá a su vez de las condiciones específicas del caso en particular para determinar si el cambio de ciertas circunstancias implica una violación al $\mathrm{TJE}^{8}$. Adicionalmente, otro punto de la discusión radica en si este estándar es el mismo o uno más exigente que el requerido por la costumbre internacional, aunque al parecer sí se lo considera como un estándar independiente y más exigente que el estándar mínimo internacional ${ }^{9}$.

A pesar de que el alcance y parámetros de las situaciones que configuran un trato justo y equitativo están en desarrollo, es posible encontrar consideraciones básicas. El TJE no implica un trato equitativo necesariamente, se ha mantenido que es un estándar absoluto, que supone que se dé un tratamiento con un cierto nivel mínimo a la inversión extranjera, y que es independiente del trato que un Estado puede dar a sus nacionales ${ }^{10}$. Es decir, el trato que se brinde a nacionales no necesariamente refleja el trato que debe recibir un inversionista extranjero a los ojos del derecho internacional.

De esta forma, el TJE es objeto de constantes interpretaciones y posiblemente más variables surgirán dentro de este estándar con el tiempo. El TJE se expresa como una serie de obligaciones que los Estados deben respetar, pero no tiene un concepto definido. Lo que sí es claro, sin embargo, es que limita hasta cierto punto la actuación de un Estado y da garantías a un inversionista. No obstante, esto no implica que un inversionista no deba ser lo

8. M. KInNEAR, “The Fair and Equitable Treatment Standard" en A. BJorkLund (Ed.), et al, Investment Treaty Law. Current Issues III: Remedies in International Investment Law. Emerging Jurisprudence of International Investment Law, British Institute of International and Comparative Law, Londres 2009, p. 226.

9. Véase, M. PAPARINSKIS, N. 2.

10. Ídem, pp. 224-225 
suficientemente diligente al evaluar el entorno y situación de un país antes de realizar su inversión, o que las condiciones que presenta un país sean inmutables en el tiempo. La pregunta que surge entonces es si su imprecisión o la no exhaustividad de los escenarios que afecta -como en el caso del concepto de inversiónes en realidad positivo, o si representa fuente de inseguridad y de posibles extralimitaciones.

Son varios enfoques desde los cuales se puede analizar a este estándar. MiLLES, por ejemplo, lo analiza desde el punto de vista regulatorio, concretamente desde la perspectiva ambiental. Señala que la clave para determinar si ha habido un TJE -O un trato injusto e inequitativo- se requiere analizar las legítimas expectativas del inversionista extranjero al entorno regulatorio de un país, y si se respetó el debido proceso. De esta forma, analiza las tensiones entre las legítimas expectativas del inversionista, y la estabilidad del ordenamiento jurídico y del entorno comercial. Finalmente, reflexiona sobre el desarrollo de un sistema más proactivo para la protección del Estado receptor de la inversión ${ }^{11}$.

Adicionalmente, tal como lo aborda PAUWELYN, es importante tomar en cuenta por qué los Estados aceptaron, y continúan aceptando, limitar sus poderes soberanos en favor de inversionistas extranjeros, y abrir la posibilidad de someter las controversias Inversionista-Estado directamente a tribunales arbitrales ${ }^{12}$. Acordemente, VIÑUALES analiza la soberanía y cómo compatibilizarla con el derecho de la inversión extranjera. Considera que es necesaria la identificación y análisis del concepto de soberanía y su aplicación en el derecho de la inversión extranjera. En especial, señala que es importante el análisis de ciertos elementos específicos, como por ejemplo las cláusulas amplias de $\mathrm{TJE}^{13}$.

11. K. Milles, The Origins of International Investment Law: Empire, Environment and the Safeguarding of Capital, Cambridge University Press, 2015.

12. J. PAuWELYN, "Rational Design or Accidental Evolution? The Emergence of International Investment Law”, en Z. Douglas (Ed.), et al, The Foundations of International Investment Law: Bringing Theory Into Practise, Oxford University Press, 2014.

13. J. Viñuales, "Sovereignty in Foreign Investment Law", en Z. Douglas (Ed.), et al, The Foundations of International Investment Law: Bringing Theory Into Practice, Oxford University Press, 2014. 
Finalmente, y no menos importante, es transcendental tener en cuenta los diferentes regímenes de los que se deriva o toma elementos el derecho de inversiones (e.g. Derecho Internacional Humanitario, derechos de terceras partes, y protección diplomática). PAPARINSKIS indica que diferentes analogías conducen a diferentes resultados en la aplicación práctica respecto a reglas de interpretación, desarrollo de legislación, y responsabilidad de los Estados. Es decir, las soluciones aportadas por otros regímenes de derecho internacional pueden aportar a la solución de los retos enfrentados por el derecho de inversiones ${ }^{14}$.

Los conceptos "justo" y "equitativo" son en sí subjetivos, por lo que su sentido corriente (plain meaning) puede no ser suficiente al interpretar el estándar, especialmente si se toma en cuenta que las partes pueden provenir de sistemas de diferente tradición legal, en donde incluso están presentes diferencias culturales. Su falta de definición, no obstante, da lugar a flexibilidad para circunstancias que puedan surgir en el futuro ${ }^{15}$.

BISHOP, CRAWFORD y REISMAN sugieren que, si bien la interpretación de las partes en una disputa de inversión es subjetiva, la aplicación del estándar de TJE es objetivo, puesto que será un tercero (i.e. un tribunal) quien lo determine ${ }^{16}$. Indican también que bajo derecho consuetudinario internacional los inversionistas tienen derecho a un cierto nivel de trato, pero que es difícil determinar si la mayoría de los países han aceptado que se debe aplicar el estándar mínimo internacional a los tratados de inversión cuando no lo han incorporado expresamente ${ }^{17}$. Adicionalmente, sugieren que el TJE no es sinónimo del estándar mínimo internacional, que ambos estándares pueden coincidir en ciertos aspectos, pero que el garantizar un TJE en un tratado de inversión no incorpora automáticamente al estándar mínimo internacional, y que la cuestión radicará en si las accio-

14. M. Paparinskis, "Analogies and Other Regimes of International Law", en Z. Douglas (Ed.), et al, The Foundations of International Investment Law: Bringing Theory Into Practise, Oxford University Press, 2014.

15. D. Bishop, J. Crawford, y M. Reisman, Foreign Investment Disputes: Cases, Materials and Commentary, Kluwer Law International, 2005, p. 1011.

16. Ídem, p. 1012.

17. Ídem, pp. 1012-1013. 
nes del caso en particular son justas y equitativas o injustas e inequitativas $^{18}$.

Existe en consecuencia un debate respecto a si el estándar representa un concepto independiente o si este es auto contenido, aunque la referencia adicional a derecho internacional podría hacer aparente que los estándares de derecho internacional son consistentes con el TJE ${ }^{19}$.

\subsection{El estándar mínimo internacional y su relación con el TJE}

El Profesor MARTINS PAPARINSKIS indica que al estándar mínimo internacional se lo considera como una regla de derecho internacional y que las disputas respecto al TJE contempladas en instrumentos internacionales son parte de su desarrollo ${ }^{20}$. Así, si el TJE no es un término nuevo en tratados internacionales, sino uno que hace referencia al derecho consuetudinario, también sería relevante tomar en cuenta la práctica por parte de los Estados y si hay opinio juris (posiblemente en los memoriales de los Estados en arbitrajes) ${ }^{21}$.

En cuanto a su contenido, es necesario precisar que en un inicio, la creación y desarrollo del estándar internacional se enfocó en la no discriminación de extranjeros (aliens) y en el ámbito de denegación de justicia ${ }^{22}$. PAPARINSKIS identifica sus etapas: (i) la primera se enfocó en el tratamiento no discriminatorio de extranjeros y en la denegación de justicia; (ii) la segunda, en la no ex-

18. Ídem, p. 1013.

19. R. Dolzer y M. Stevens, "Bilateral Investment Treaties" Kluwer 1995, en D. Bishop, J. Crawford y M. REISMAN, pp. 1013-1014. En el acuerdo NAFTA (TLCAN) el TJE está subsumido al estándar mínimo internacional consuetudinario. Véase, Nota Interpretativa de 31 de julio de 2001 de la Comisión de Libre Comercio del Art. 1105(1) de dicho acuerdo. Véase, F. GonzÁlez DE Cossío "Trato Justo y Equitativo en Arbitraje de Inversión: Un Ejercicio Interpretativo”, «https://goo.gl/qYJa78».

20. M. Paparinskis, N. 2, pp. 11-2: Mínimo se refiere a lo menos permisible y no a lo menos posible. Véase, R.Y. JENnINGS, "General Course in International Law" (1961) 37 BYIL 156, p. 181 en PAPARINSKIS, N. 13: "of course the qualification "minimum" standard means the least permissible, and not the least possible".

21. Ídem, pp. 14-18.

22. Ídem, pp. 47-53. Véase, LFH Neer y Pauline Neer (Estados Unidos de América c. México) (1926) 4 RIAA 60. PAPARINSKIS indica que "Neer operates as the default rule, extrapolated by analogy from denial of justice $[\ldots]$.". 
haustividad del aspecto de no discriminación del estándar; y (iii) la tercera, en el caso LFH Neer y Pauline Neer ${ }^{23}$.

Posteriormente, después de la Segunda Guerra Mundial, entraría en discusión ya no solo la protección de personas naturales, sino también de inversionistas corporativos ${ }^{24}$. Así, los argumentos de la práctica o jurisprudencia europea de derechos humanos serían utilizados por tribunales de inversión para clarificar la ley existente, de forma interpretativa, o por analogía, como, por ejemplo, el concepto de propiedad, denegación de justicia, expropiación, proporcionalidad, compensación, etc ${ }^{25}$.

PAPARINSKIS señala que el uso del término fair and equitable, o lenguaje similar, ya era usado desde antes de la Segunda Guerra Mundial, y que usualmente estaría relacionado con el comercio de mercancías ${ }^{26}$. La discusión alrededor del TJE y su contenido, sin embargo, se acentuaría con el desarrollo de los instrumentos internacionales y, concretamente, con los arbitrajes de inversión Inversionista-Estado.

Después de la Segunda Guerra Mundial hubo varios intentos de acuerdos multilaterales que abordaron de cierta forma el término, pero estas iniciativas fracasaron ${ }^{27}$. En consecuencia, otra corriente adquiriría protagonismo y los Estados incluyeron reglas de TJE -usualmente como una obligación separada- en los tratados bilaterales de protección recíproca de inversiones suscritos con sus pares ${ }^{28}$.

Tal como se mencionó anteriormente, la pregunta que surge entonces es si el TJE es igual al estándar mínimo internacional, si

23. Ídem, p. 64.

24. Ídem, Véase también, Barcelona Traction, Light and Power Company, Limited (Bélgica c. España) (1970) CIJ. En este caso se trató la relación entre Derechos Humanos y la protección a inversionistas.

25. Ídem, pp. 81-82.

26. Ídem, pp. 84-89. El autor cita, por ejemplo, el uso de Right and Justice, en un tratado suscrito por Gran Bretaña y Suecia en 1654, y el uso de justice and equity, en un tratado de paz y comercio celebrado entre Gran Bretaña y Dinamarca en 1670.

27. Ibíd, pp. 90-2. Véase, 1947 Havana Charter of the international trade organization (just and equitable treatment); 1948 Economic Agreement of Bogota (equitable treatment); 1959 Abs-Shawcross Draft Convention (fair and equitable treatment).

28. Ídem, p. 93. 
este es independiente de la práctica consuetudinaria, o si se trata de un híbrido. Dado el régimen descentralizado del arbitraje de inversión, se han dado diferentes enfoques y en algunos casos se ha equiparado al TJE con el estándar mínimo consuetudinario, como un estándar independiente de la costumbre, o un enfoque intermedio ${ }^{29}$. Por último, se sugiere que las reglas de TJE consagradas en los TBIs hacen referencia al estándar consuetudinario $\mathrm{o}$, por lo menos, requiere que se lo tome en cuenta para poder interpretarlo ${ }^{30}$.

\subsection{Contenido del TJE}

Dado que el TJE está contemplado en instrumentos internacionales, es necesario referirse a las reglas de interpretación establecidas en la Convención de Viena sobre el Derecho de los Tratados $^{31}$. La interpretación debe realizarse en el contexto del tratado, a la luz de su objeto y fin. De acuerdo a lo indicado por PAPARINSKIS, la costumbre puede ser relevante y podría incluso tomarse en cuenta la práctica internacional relacionada con el TJE

29. Ibíd, pp. 94-5, 160.

30. Ibíd, pp. 95, 102.

31. Convención de Viena sobre el Derecho de los Tratados, Ratificada mediante Decreto Ejecutivo No. 619, RO No. 134, 28/07/2003.

Art. 31.- Regla general de interpretación

1. Un tratado deberá interpretarse de buena fe conforme al sentido corriente que haya de atribuirse a los términos del tratado en el contexto de éstos y teniendo en cuenta su objeto y fin.

2. Para los efectos de la interpretación de un tratado, el contexto comprenderá, además del texto, incluidos su preámbulo y anexos:

a) Todo acuerdo que se refiera al tratado y haya sido concertado entre todas las partes con motivo de la celebración del tratado; $y$,

b) Todo instrumento formulado por una o más partes con motivo de la celebración del tratado y aceptado por las demás como instrumento referente al tratado.

3. Juntamente con el contexto, habrá de tenerse en cuenta:

a) Todo acuerdo ulterior entre las partes acerca de la interpretación del tratado o de la aplicación de sus disposiciones;

b) Toda práctica ulteriormente seguida en la aplicación del tratado por la cual conste el acuerdo de las partes acerca de la interpretación del tratado; y,

c) Toda norma pertinente de derecho internacional aplicable en las relaciones entre las partes.

4. Se dará a un término un sentido especial si consta que tal fue la intención de las partes.

Art. 32.- Medios de interpretación complementarios

Se podrá acudir a medios de interpretación complementarios, en particular a los trabajos preparatorios del tratado y a las circunstancias de su celebración, para confirmar el sentido resultante de la aplicación del artículo 31, o para determinar el sentido cuando la interpretación dada de conformidad con el artículo 31:

a) Deje ambiguo u oscuro el sentido; o,

b) Conduzca a un resultado manifiestamente absurdo o irrazonable. 
en reglas pari materia desarrollada por tribunales internacionales. Así, sugiere que la Convención de Viena da dos vías para introducir a la costumbre internacional en el proceso de interpretación: el sentido corriente o sentido especial pueden hacer referencia directa a la costumbre (Art. 31(1) y Art. 31(4)), y que la costumbre relevante podría tomarse en cuenta en el contexto del artículo $31(3)(c)^{32}$. Surge entonces la pregunta en cuanto a la importancia de la costumbre en el proceso interpretativo.

PAPARINSKIS concluye que el significado ordinario de TJE es una referencia al estándar mínimo internacional -especialmente respecto a la administración de justicia- y que el contenido de la regla consuetudinaria informa sobre el significado ordinario del término en el tratado ${ }^{33}$. Adicionalmente, afirma que el derecho consuetudinario puede ser tomado en cuenta incluso si no se acepta el argumento de que el TJE hace referencia al estándar mínimo consuetudinario, toda vez que la Convención de Viena (Art. 31(3)(c)) permite considerar normas de derecho internacional aplicable y que la relevancia del derecho consuetudinario es incuestionable, aunque su peso interpretativo dependería del caso concreto, el cual sería el mismo que el contexto del tratado ${ }^{34}$

\subsection{Contenido del estándar mínimo internacional: administración de justicia y protección de propiedad}

Actualmente no existe una práctica estatal tan amplia y consistente, ni opinio juris, como para que se la considere como derecho consuetudinario; sin embargo, esta puede ser relevante ${ }^{35}$. Se afirma que el TJE aplica incuestionablemente a la administración de justicia y que los tribunales arbitrales han aceptado que las reglas de TJE hacen referencia al derecho consuetudinario de denegación de justicia ${ }^{36}$. PAPARINSKIS establece el contenido del

32. M. PAPARINSKIS, N. 2, p. 155.

33. Ídem, pp. 163-165.

34. Ídem, pp. 166-171.

35. Ídem, p. 171.

36. Ídem, p. 181. Véase, C. Muriel Bedoya, "Chevron and the Ecuadorian Torpedo", Cambridge International Law Journal, 22/12/2016, «http://cilj.co.uk/2016/12/22/chevron-and-the-ecuadoriantorpedo/». 
estándar de administración de justicia en tres pasos: (i) basándose en derecho consuetudinario clásico de denegación de justicia para proveer su contexto; (ii) llenado por razonamiento de derechos humanos; y (iii) confirmado por casos de inversión ${ }^{37}$.

Así, se han desarrollado normas para que la denegación de justicia se configure como, por ejemplo, el agotamiento del sistema judicial local, que exista independencia de otras funciones del Estado, o que el cumplimiento de normas locales no necesariamente excluye el cometimiento de una violación de derecho internacional ${ }^{38}$. Ha sido generalmente aceptado que se deben agotar los remedios locales para que se configure denegación de justicia, sin embargo, su alcance y contenido no están determinados con certeza absoluta ${ }^{39}$. Por ejemplo, se ha discutido si es razonable no agotar dichos remedios o si los existentes son remedios adecuados, etc.

En cuanto a la protección de propiedad, al igual que en el caso de administración de justicia, también debe ser analizado el lenguaje del tratado, la costumbre puede ser relevante, así como argumentos comparativos de otras ramas (e.g. derechos humanos), y los casos de inversión ${ }^{40}$. PAPARINSKIS señala que el punto de partida es el alcance y contenido del derecho de expropiación indirecta y la legalidad de la expropiación directa, y que el estándar de protección de propiedad es diferente del derecho de expropiación, en el que no se requiere interferencia con derechos de propiedad. Si los argumentos de tratados de Derechos Humanos pueden ser usados para explicar reglas análogas de protección de inversiones -bajo el Art. 31(3)(c) de la Convención de Viena- en consecuencia, si las partes del tratado de inversión también son partes de un tratado de Derechos Humanos, se vuelve material de interpretación admisible la interpretación hecha por una corte de derechos humanos por su relevancia ${ }^{41}$.

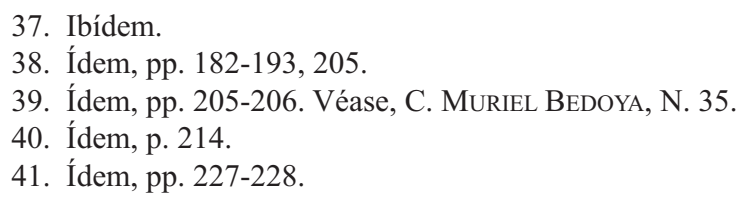


Es muy importante, sin embargo, mantener presente las diferencias de otros regímenes con el derecho internacional de inversiones. El derecho de inversiones tiene reglas diferentes -por ejemplo, para expropiación- y el sistema de derechos humanos con el que se lo pretendería comparar puede no reconocer derechos a entidades legales, sino solo a indivi$\operatorname{duos}^{42}$.

\subsection{Estándar moderno y protección de propiedad}

Son diferentes elementos los que forman $-\mathrm{O}$ al menos se alega que lo hacen- el estándar moderno ${ }^{43}$ :

- Arbitrariedad

- Buena fe

- Discriminación

- Transparencia

- Debido proceso

- Expectativas

Un trato arbitrario puede ser uno opuesto al estado de derecho, que no toma en cuenta en debido proceso ${ }^{44}$. Por su parte, la buena fe puede ser relevante para complementar otros aspectos del estándar internacional. Actuar de buena fe es un principio que ya está implícito en el ordenamiento legal internacional e, interesantemente, PAPARINSKIS comenta que los casos más extremos de arbitrariedad pueden ser explicados desde la mala $\mathrm{fe}^{45}$. La discriminación también es parte del estándar internacional, e implica el requerir justificaciones razonables para un tratamiento diferente en casos similares ${ }^{46}$. Por otro lado, la transparencia se configura como la previsibilidad de la ley y su aplicación (o por su falta de previsibilidad $)^{47}$. En cuanto al debido proceso, las segu-

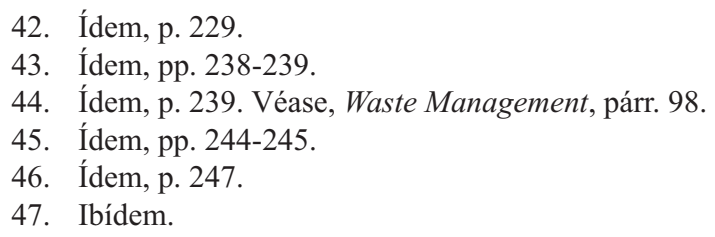


ridades procesales son muy importantes en la interpretación del estándar internacional ${ }^{48}$.

Finalmente, las legítimas o razonables expectativas del inversionista podrían ser el elemento de mayor alcance del estándar internacional ${ }^{49}$. Existen, sin embargo, diferentes variables que lo determinarían y pueden haber, por ejemplo, actos unilaterales que obliguen a un Estado ${ }^{50}$. Así, por ejemplo, un incumplimiento contractual por parte de un Estado no necesariamente configura una violación de derecho internacional, pero también pueden haber otras variables -como cláusulas de estabilización o cláusulas paraguas- que sí podrían dar lugar a responsabilidad internacional.

Es razonable concluir que el estándar mínimo internacional se refleja en las reglas de instrumentos internacionales, como por ejemplo las que regulan el TJE. El derecho consuetudinario, y el de otras ramas del derecho internacional pueden ser relevantes, pero su alcance y desarrollo todavía están en constante evolución. En el siguiente apartado se observará cómo se ha recogido el TJE en los tratados bilaterales de inversión suscritos por la República del Ecuador.

\section{EL TRATO JUSTO Y EQUITATIVO EN LOS TRATADOS BI- LATERALES DE INVERSIÓN ECUATORIANOS Y SU TRA- TAMIENTO POR LOS TRIBUNALES ARBITRALES DE INVERSIÓN}

Ecuador suscribió varios Tratados Bilaterales de Inversión (TBIs) en las últimas décadas. En esta parte se revisará cómo está contemplado el TJE en los textos de los TBIs suscritos con Alemania, Argentina, Bolivia, Canadá, Chile, China, Estados

48. Por ejemplo, es transcendental al momento de discutir una expropiación y muy relevante al analizar un caso en el que se alegue denegación de justicia.

49. Ídem, p. 251.

50. Ídem, pp. 251-252. PAPARINSKIS señala que las expectativas del inversionista derivadas de un acto unilateral podrían operar autónomamente de las reglas de un TBI, aunque podrían también ser cubiertas si existen reglas amplias de jurisdicción o nación más favorecida en el mismo TBI. 
Unidos de América, España, Finlandia, Francia, Italia, Países Bajos, Perú, Reino Unido, Suecia, Suiza, y Venezuela ${ }^{51}$. Posteriormente, se analizará cómo han interpretado el TJE los tribunales de inversión en los casos en los que Ecuador ha sido parte.

\subsection{El trato justo y equitativo en los TBIs ecuatorianos}

El TJE ha sido expresamente reconocido por la República del Ecuador. A continuación, se resumirá cómo se lo ha recogido en diferentes TBIs. Es importante notar que desde el año 2009 se iniciaron procedimientos formales para denunciar los TBIs que se analizarán a continuación. En el año 2010 se emitió el decreto ejecutivo de denuncia del TBI finlandés, y el pasado mayo de 2017 el ex Presidente Rafael Correa emitió los decretos ejecutivos en los que se decretó denunciar y declarar terminados los TBIs restantes. En los mismos decretos se dispuso la notificación a los estados contrapartes de estos instrumentos, pero de la información pública disponible no se ha confirmado si dichas notificaciones

51. Véase, Tabla: Tratados Bilaterales de Inversión Ecuatorianos. Los textos de todos estos TBIs, excepto el de Italia, fueron publicados adicionalmente a su publicación individual, en el Tomo II del Suplemento del Registro Oficial No. 153 de 25 de noviembre de 2005. Ecuador también suscribió TBIs con otros países y en algunos de estos se hace referencia expresa al TJE. Los siguientes tratados ya no se encuentran vigentes o han sido denunciados: Costa Rica, suscrito el 05 de diciembre de 2001 (no entró en vigencia por falta de procedimientos por parte de Costa Rica); Cuba, suscrito el 06 de mayo de 1997 (denunciado por Ecuador); El Salvador, suscrito el 15 de mayo de 1994 (denunciado por Ecuador); Guatemala, suscrito el 14 de agosto de 2002 (el 17 de enero de 2008 se comunica la denuncia del TBI); Honduras, suscrito el 26 de junio de 2000 (denunciado por Ecuador); Nicaragua, suscrito el 02 de junio de 2000 (denunciado por Ecuador); Paraguay, suscrito el 28 de enero de 1994 (denunciado por Ecuador); República Dominicana, suscrito el 26 de junio de 1998 (Denunciado por Ecuador); Rumania, suscrito el 21 de marzo de 1996 (denunciado por Ecuador); Rusia, suscrito el 25 de abril de 1996 (no vigente, Rusia no lo ratificó); Uruguay, suscrito el 31 de julio de 1985 (denunciado por Ecuador). Fuente: Ministerio de Relaciones Exteriores y Movilidad Humana, Oficio No. MREMH-CGJ-20150236-OF, de 21 de agosto de 2015, remitido al autor. En el RO No. 452, 23/10/2008 se publicó la Nota No. 5084/GVMIDGPEI/DGT/08 del Ministerio de Relaciones Exteriores, de 30 de enero de 2008, por la cual se comunica a las Embajadas de Cuba, El Salvador, Guatemala, Honduras, Nicaragua, Paraguay, República Dominicana y Uruguay, que el 17 de enero de 2008 se instruyó a la Embajada del Ecuador en estos países que presente la denuncia de los TBIs suscritos con dichos países. En la Nota se indica que Ecuador "se encuentra realizando una revisión de su sistema jurídico y de la política nacional e internacional en materia de inversiones", que cada TBI en mención "no ha logrado alcanzar su objetivo fundamental, es decir, motivar la atracción de capitales para la inversión productiva bilateral" y que "tan pronto se haya definido el nuevo marco jurídico y se cuente con un Modelo de Acuerdo acorde a dicho esquema se podría retomar la negociación de instrumentos similares. Asimismo, el Ecuador privilegiará el tratamiento de temas de inversión en el contexto de esquemas de integración económicos más amplios." 
ya han sido realizadas. Todos los TBIs, sin embargo, cuentan con una cláusula de supervivencia ${ }^{52}$.

\subsubsection{TBI Ecuador-Alemania ${ }^{53}$}

En este TBI se menciona al TJE en su preámbulo y en el Artículo 2(1):

RECONOCIENDO que un Convenio sobre el tratamiento que debe acordarse a dichas inversiones estimulará el flujo de capital y tecnología y el desarrollo económico de las Partes Contratantes y que es deseable un trato justo y equitativo de las inversiones [...]

ARTICULO 2. - Fomento de Inversiones

(1) Cada una de las Partes Contratantes, de acuerdo con sus disposiciones legales vigentes, permitirá dentro de su respectivo territorio, las inversiones de capital de nacionales o sociedades de la otra Parte Contratante, promoviéndolas en lo posible. En todo caso tratará justa y equitativamente a las inversiones de capital (Énfasis añadido).

\subsubsection{TBI Ecuador-Argentina ${ }^{54}$}

Art. 3.- Protección de inversiones

(1) Cada Parte Contratante asegurará en todo momento un tratamiento justo y equitativo a las inversiones de inversores de la otra Parte Contratante y no perjudicará su gestión, mantenimiento, uso, goce o disposición a través de medidas injustificadas o discriminatorias (Énfasis añadido).

52. Véase, Tabla: Tratados Bilaterales de Inversión Ecuatorianos. La mayoría de TBIs establece un periodo de supervivencia de diez o quince años desde la fecha de terminación. Las excepciones son el TBI Ecuador-Italia, con cinco años; y, el TBI Ecuador - Reino Unido, con veinte años.

53. El Tratado Entre la República del Ecuador y la República Federal de Alemania Sobre Fomento y Recíproca Protección de Inversiones de Capital y su Protocolo fueron suscritos el 21/03/1996, ratificado mediante Decreto Ejecutivo No. 335, 23/05/1997, RO No. 84, 11/06/1997.

54. El Convenio Entre el Gobierno de la República del Ecuador y el Gobierno de la República Argentina para la Promoción y Protección Reciproca de Inversiones fue suscrito el 18/02/1994, ratificado mediante Decreto Ejecutivo No. 2996, 21/08/1995, RO No. 785, 20/09/1995. 


\subsubsection{TBI Ecuador-Bolivia ${ }^{55}$}

Art. 3.- Protección de Inversiones

(1) Cada Parte Contratante asegurará en todo momento un tratamiento justo y equitativo a las inversiones de inversionistas de la otra Parte Contratante, y no perjudicará su gestión, mantenimiento, uso, goce o disposición a través de medidas injustificadas o discriminatorias (Énfasis añadido).

\subsubsection{TBI Ecuador-Canadá $a^{56}$}

Art. II.- Establecimiento, Adquisición y Protección de las Inversiones

2. Ambas Partes Contratantes tratarán a las inversiones o los beneficios de los inversionistas de la otra Parte Contratante.

(a) de modo justo y equitativo de acuerdo con los principios del derecho internacional; y

(b) les proporcionarán protección y seguridad totales (Énfasis añadido).

\subsubsection{TBI Ecuador-Chile ${ }^{57}$}

Art. 4.- Protección de Inversiones

(1) Cada Parte Contratante asegurará en todo momento un tratamiento justo y equitativo a las inversiones de inversionistas de la otra Parte Contratante y no perjudicará su gestión, mantenimiento, uso, goce, usufructo, ampliación, liquidación o disposición, a través de medidas injustificadas o discriminatorias (Énfasis añadido).

55. El Convenio Entre la República del Ecuador y la República de Bolivia Para la Promoción y Protección Recíproca de Inversiones fue suscrito el 25/05/1995, ratificado mediante Decreto Ejecutivo No. 352B de 02/06/1997, RO No. 159, 24/09/1997.

56. El Convenio Entre el Gobierno del Ecuador y el Gobierno de Canadá Para el Fomento y Protección Recíproca de Inversiones fue suscrito el 29/04/1996, ratificado mediante Decreto Ejecutivo No. 352B de 2/06/1997, RO No. 105, 10/07/1997.

57. El Convenio Entre El Gobierno de la República del Ecuador y el Gobierno de la República de Chile Para la Promoción y Protección Recíprocas de Inversiones fue suscrito el 27/10/1993, ratificado mediante Decreto Ejecutivo No. 2996 de 21/08/1995, RO No. 785, 20/09/1995. 


\subsubsection{TBI Ecuador-China ${ }^{58}$}

Artículo 3(1).- Las inversiones de cualquiera de las Partes Contratantes y las actividades relacionadas con las mismas gozarán de un tratamiento justo y equitativo, así como de protección en el territorio de la otra Parte Contratante (Énfasis añadido).

\subsubsection{TBI Ecuador-Estados Unidos de América ${ }^{59}$}

En este TBI se menciona al TJE en su preámbulo y en el Artículo II(3)(a):

Conviniendo en que, a los fines de mantener un marco estable para las inversiones y la utilización más eficaz de los recursos económicos, es deseable otorgar un trato justo y equitativo a las inversiones [...]

Art. II

3. a) Las inversiones, a las que se concederá siempre un trato justo y equitativo, gozarán de protección y seguridad plenas $\mathrm{y}$, en ningún caso, se les concederá un trato menos favorable que el que exige el derecho internacional (Énfasis añadido).

\subsubsection{TIB Ecuador-España ${ }^{60}$}

Art. IV.- Tratamiento

1. Cada Parte Contratante garantizará en su territorio un tratamiento justo y equitativo a las inversiones realizadas por inversionistas de la otra Parte Contratante (Énfasis añadido).

58. El Convenio Entre el Gobierno de la República del Ecuador y el Gobierno de la República Popular de China Para el Fomento y Protección Recíprocos de Inversiones fue suscrito el 21/03/1994, ratificado mediante Decreto Ejecutivo No. 352-B de 2/06/1997, RO No. 104, 9/07/1997.

59. El Tratado Entre la República del Ecuador y los Estados Unidos de América Sobre Promoción y Protección Recíproca de Inversiones fue suscrito el 27/08/1993, ratificado mediante Decreto Ejecutivo No. 3143 de 13/10/1995, RO No. 49, 22/04/1997.

60. El Acuerdo Para la Promoción y Protección Recíproca de Inversiones Entre el Reino de España y la República del Ecuador fue suscrito el 26/06/1996, RO No. 106, 11/07/1997. 


\subsubsection{TBI Ecuador-Finlandia ${ }^{61}$}

En este TBI se menciona al TJE en su preámbulo y en el Artículo 3:

DESEOSOS de intensificar la cooperación económica para el beneficio mutuo de ambos países y mantener condiciones justas, equitativas y favorables para las inversiones de inversionistas de una de las Partes Contratantes en el territorio de la otra Parte Contratante $[\ldots]$

Artículo 2. - Promoción y Protección de Inversiones

2.- Cada una de las Partes Contratantes acordará en todo momento en su territorio a las inversiones de los inversionistas de la otra Parte Contratante un tratamiento justo y equitativo y protección y seguridad totales y constantes (Énfasis añadido).

\subsubsection{TBI Ecuador-Francia ${ }^{62}$}

Art. 4.- Cada una de las Partes Contratantes se compromete a garantizar un trato justo y equitativo, conforme a los principios del Derecho Internacional a las inversiones de los nacionales y sociedades de la otra Parte Contratante y a hacer lo necesario para que el ejercicio del derecho así reconocido no se vea obstaculizado ni en derecho ni de hecho.

En particular aunque no exclusivamente, se considerará como obstáculo de derecho y de hecho al trato justo y equitativo, cualquier restricción a la adquisición y al transporte de materias primas y materias auxiliares, de energía y combustibles,

61. El Convenio Entre el Gobierno de la República del Ecuador y el Gobierno de la República de Finlandia Sobre la Promoción y Protección de Inversiones fue suscrito el 18/04/2001, ratificado mediante Decreto Ejecutivo No. 1756 de 13/08/2001, RO No. 483, 28/12/2001. Mediante Decreto Ejecutivo No. 576 de 9/12/2010, el Presidente de la República decretó denunciarlo y declararlo terminado, derogar el Decreto Ejecutivo No. 1756 de 13/08/2001, por el cual se lo ratificó, y ordenó su notificación a la República de Finlandia. El Decreto Ejecutivo No. 576 fue publicado en el RO No. 345, 21/12/2010. El TBI establece en su Artículo 14 que tiene una vigencia de diez años y que, a menos que se envíe una notificación oficial de terminación doce meses antes de la expiración de su periodo de validez, será extendido tácitamente por periodos adicionales de diez años. La información pública disponible no indica esta fecha; sin embargo, el TBI cuenta con una cláusula de supervivencia, en la que se señala que: “(2) Con respecto de aquellas inversiones efectuadas antes de la fecha de aplicación de la notificación de expiración de este Convenio, las disposiciones de los Artículos 1 a 13 seguirán vigentes por un periodo de diez años desde la fecha de terminación".

62. El Convenio Entre el Gobierno de la República del Ecuador y el Gobierno de la República Francesa Para la Promoción y Protección Reciprocas de Inversiones fue suscrito el 07/09/1994, ratificado mediante Decreto Ejecutivo No. 2996 de 21/08/1995, RO No. 778, 11/09/1995. 
así como de medios de producción y explotación de cualquier tipo, igualmente cualquier obstáculo a la venta y al transporte de los productos dentro y fuera del país y en el extranjero, así como cualquier otra medida que tuviere efecto análogo (Énfasis añadido).

\subsubsection{TBI Ecuador-Italia ${ }^{63}$}

Art. 2.- Promoción y Protección de Inversiones

3. Ambas Partes Contratantes garantizarán en todo momento un tratamiento justo y equitativo a las inversiones de inversionistas de la otra Parte Contratante. Ambas Partes Contratantes garantizarán que la gestión, mantenimiento, uso, transformación, goce o cesión de las inversiones efectuadas en su territorio por inversionistas de la otra Parte Contratante, así como las compañías y empresas en las que dichas inversiones han sido efectuadas, no serán en ningún modo sometidas a medidas injustificadas o discriminatorias (Énfasis añadido).

\subsubsection{TBI Ecuador-Países Bajos ${ }^{64}$}

En este TBI se menciona al TJE en su preámbulo, así como en el Artículo 3:

RECONOCIENDO que un Convenio sobre el tratamiento que debe acordarse a dichas inversiones estimulará el flujo de capital y tecnología y el desarrollo económico de las Partes Contratantes y que es deseable un trato justo y equitativo de las inversiones [...]

Art. 3.- Tratamiento general

1. Cada una de las Partes Contratantes garantizará un tratamiento justo y equitativo a las inversiones de los inversionistas de la otra Parte Contratante y no impedirá mediante medidas irrazonables o discriminatorias, la operación, manejo, mantenimiento,

63. El Convenio Entre el Gobierno de la República del Ecuador y el Gobierno de la República Italiana Sobre la Promoción y Protección de Inversiones fue suscrito el 25/10/2001 y ratificado mediante Decreto Ejecutivo No. 544-A de 25/06/2003.

64. El Convenio Para la Promoción y Protección Recíproca de Inversiones Entre la República del Ecuador y el Reino de Los Países Bajos fue suscrito el 27/06/1999, ratificado mediante Decreto Ejecutivo No. 1412-C de 5/04/2001, RO No. 406, 6/09/2001. 
uso, goce o enajenación de las mismas por dichos inversionistas. Cada una de las Partes Contratantes acordará a dichas inversiones plena protección y seguridades físicas (Énfasis añadido).

\subsubsection{TBI Ecuador-Perú 65}

En este TBI se menciona al TJE en su preámbulo, así como en el Artículo 3:

ANIMADOS del propósito de crear y mantener condiciones justas, equitativas y favorables para las inversiones de inversionistas de una de las Partes Contratantes en el territorio de la otra Parte Contratante [...]

Art. 3.- Tratamiento de Inversiones

1. Cada Parte Contratante asegurará un tratamiento justo y equitativo para las inversiones de los inversionistas de la otra Parte Contratante realizadas de conformidad con el presente Convenio y no impedirá, con medidas arbitrarias o discriminatorias, la libre administración, utilización, uso, goce o disposición de las inversiones de los inversionistas de esa Parte Contratante (Énfasis añadido).

\subsubsection{TBI Ecuador-Reino Unido ${ }^{66}$}

\section{Art. 2.- PROMOCION Y PROTECCION DE INVERSIONES.-} (sic)

(2) Las inversiones de nacionales y compañías de cada una de las partes contratantes recibirán un tratamiento justo y equitativo y deberán gozar de total protección y seguridad en el territorio de la otra parte contratante. Ninguna parte contratante podrá de ninguna manera impedir mediante medidas irrazonables o discriminatorias la gestión, mantenimiento, uso, goce o enajenación de inversiones de nacionales o compañía de otra

65. El Convenio Entre el Gobierno de la República del Ecuador y el Gobierno de la República del Perú Sobre la Promoción y Protección Recíproca de Inversiones fue suscrito el 7/04/1999, ratificado mediante Decreto Ejecutivo No. 1325-A de 1/10/1999, RO No. 341, de 17/12/1999.

66. El Convenio Entre el Gobierno del Reino Unido de Gran Bretaña e Irlanda del Norte y el Gobierno de la República del Ecuador Para la Promoción y Protección de Inversiones fue suscrito el 10/05/1994, ratificado mediante Decreto Ejecutivo No. 2996 de 21/08/1995, RO No. 778, 11/09/1995. 
parte contratante en su territorio. Las partes contratantes deberán observar cualquier obligación que pueda haber adquirido en relación con inversiones de nacionales o compañías de la parte contratante (Énfasis añadido).

\subsubsection{TBI Ecuador-Suecia ${ }^{67}$}

En este TBI se menciona al TJE en su preámbulo, así como en el Artículo 2:

Deseosos de intensificar la cooperación económica para mutuo beneficio de ambos países y mantener condiciones justas y equitativas para las inversiones de inversionistas de una Parte Contratante en el territorio de la otra Parte Contratante. [...] Art. 2.- Promoción y Protección de Inversiones

3) Cada Parte Contratante deberá en todo momento asegurar un tratamiento justo y equitativo a las inversiones de inversionistas de la otra Parte Contratante y no deberá afectar a la administración, mantenimiento, uso, disfrute o enajenación de las mismas, así como la adquisición de bienes y servicios y la venta de su producción, a través de medidas injustificadas o discriminatorias (Énfasis añadido).

\subsubsection{TBI Ecuador-Suiza ${ }^{68}$}

Artículo Primero. - Cada una de las Altas Partes Contratantes se compromete a proteger los bienes invertidos en su territorio por los nacionales o sociedades de la otra Parte y a no poner obstáculos por medidas injustificadas o discriminatorias a la gestión, el mantenimiento, la utilización, el goce, el aumento y, dado el caso, la liquidación de esos bienes. Cada Parte otorgará las autorizaciones necesarias, especialmente en lo que se refiere a inversiones, así como a la conclusión y ejecución de contratos de licencia, de asistencia comercial, administrativa o técnica.

67. El Acuerdo Entre el Gobierno del Reino de Suecia y el Gobierno de la República el Ecuador Para la Promoción y Protección Recíproca de Inversiones fue suscrito el 31/05/2001, ratificado mediante Decreto Ejecutivo No. 2135 de 28/11/2001, RO No. 502, 25/01/2002.

68. El Acuerdo entre la República del Ecuador y la Confederación Suiza relativo a la protección y al fomento de las inversiones fue suscrito el 02/05/1968, RO No. 198, 07/04/1971. 
En particular, los nacionales o las sociedades de una de las Altas Partes Contratantes se beneficiarán, en lo que se refiere a sus bienes, en el territorio de la otra Parte, de un trato justo y equitativo, por lo menos igual al que reconoce esta Parte a sus nacionales o, si es más favorable, del trato acordado a los nacionales o a las sociedades de la nación más favorecida (Énfasis añadido).

\subsubsection{TBI Ecuador-Venezuela ${ }^{69}$}

Art. III.- PROTECCION DE INVERSIONES (sic)

1.- Cada Parte Contratante de conformidad con las normas y principios del Derecho Internacional, asegurará en todo momento un tratamiento justo y equitativo a las inversiones de inversores de la otra Parte Contratante, y no perjudicará su gestión, mantenimiento, uso, goce o disposición a través de medidas injustificadas o discriminatorias (Énfasis añadido).

\subsection{Particularidades del TJE en los TBIs ecuatorianos}

En todos los TBIs se reconoce, asegura, garantiza, concede o acuerda el TJE, y en los TBIs celebrados con Alemania, Estados Unidos, Finlandia, Países Bajos, Perú, y Suecia, incluso se lo menciona expresamente en su preámbulo. Salvo el caso del TBI celebrado con Suiza -que protege los bienes de los nacionales o sociedades de la otra Parte- en todos los tratados se hace mención al TJE de inversiones. Sin embargo, algunos de los tratados tienen particularidades especiales. Así, por ejemplo, en el TBI suscrito con Alemania, el TJE tiene como objeto las inversiones de capital, el celebrado con Canadá hace referencia a las inversiones o los beneficios de los inversionistas, y el TBI chino menciona a las inversiones y las actividades relacionadas con las mismas.

Otro elemento que se repite en varios TBIs, que acompaña al TJE, es la obligación de no mantener medidas injustificadas o dis-

69. El Convenio Entre el Gobierno de la República del Ecuador y el Gobierno de la República de Venezuela Para la Promoción y Protección Reciprocas de Inversiones fue suscrito el 18/11/1993, RO No. $548,14 / 10 / 1994$. 
criminatorias $^{70}$, o irrazonables o discriminatorias ${ }^{71}$, que puedan afectar a las inversiones. En estos TBIs es constante además la enumeración de qué actividades no deberán ser perjudicadas por medidas injustificadas/irrazonables o discriminatorias. De esta forma, coinciden homogéneamente algunos $\mathrm{TBIs}^{72}$ en que no se perjudicará la gestión, mantenimiento, uso, goce o disposición ${ }^{73}$ de las inversiones. Otros, añaden elementos adicionales como el usufructo, ampliación, liquidación ${ }^{74}$; transformación ${ }^{75}$; operación, manejo ${ }^{76}$; libre administración, utilización ${ }^{77}$; administración, disfrute, así como la adquisición de bienes y servicios y la venta de su producción ${ }^{78}$, o, en el caso de Suiza, el aumento y liquidación de bienes ${ }^{79}$.

En TBIs como los suscritos con Argentina, Bolivia, Chile y España, no se observa un desarrollo adicional del TJE. Este, sin embargo, no es el caso en otros tratados que añaden elementos que pueden representar una importante diferencia en la práctica. Así, en el tratado suscrito con Estados Unidos se garantiza la "protección y seguridad plenas"; en el suscrito con el Reino Unido, la "total protección y seguridad en el territorio de la otra parte"; en los tratados canadiense y finlandés se proporciona a las inversiones "protección y seguridad totales" en el primer caso, y "protección y seguridad totales y constantes", en el segundo; y, en el TBI suscrito con Países Bajos, se otorga "plena protección y seguridades físicas" a las inversiones.

Por otro lado, en el caso italiano, se amplía el tratamiento no solo a las inversiones, sino también a "las compañías y empresas en las que dichas inversiones han sido efectuadas". En el

70. Se utilizan estos términos en los TBIs celebrados con Argentina, Bolivia, Chile, Italia, Suecia, Suiza, Venezuela.

71. Se utilizan estos términos en los TBIs celebrados con Países Bajos y Reino Unido.

72. Los suscritos con: Argentina, Bolivia (estos dos primeros siendo idénticos), Chile, Italia, Países Bajos, Suiza, Venezuela.

73. En el TBI suscrito con Italia se habla de cesión, y en el suscrito con Países Bajos y Reino Unido se habla de enajenación.

74. TBI Ecuador-Chile.

75. TBI Ecuador-Italia.

76. TBI Ecuador-Países Bajos.

77. TBI Ecuador-Perú.

78. TBI Ecuador-Suecia.

79. TBI Ecuador-Suiza. 
TBI celebrado con Reino Unido, expresamente se añade que las "partes contratantes deberán observar cualquier obligación que pueda haber adquirido en relación con inversiones de nacionales o compañías de la parte contratante". Por último, en el TBI suizo, se señala que el TJE debe ser "por lo menos igual al que reconoce esta Parte a sus nacionales o, si es más favorable, del trato acordado a los nacionales o a las sociedades de la nación más favorecida".

Finalmente, algunos de los textos más relevantes son los previstos en los TBIs suscritos con Estados Unidos, Francia y Venezuela. Estos tres instrumentos tienen en común en que expresamente hacen referencia al derecho internacional. Así, el TBI estadounidense señala que a las inversiones "se les concederá un trato menos favorable que el que exige el derecho internacional"; el francés garantiza un TJE "conforme a los principios del Derecho Internacional a las inversiones de los nacionales y sociedades de la otra Parte"; $y$, el venezolano, asegura un TJE a las inversiones "de conformidad con las normas y principios del Derecho Internacional". En el TBI francés, incluso se elabora aún más el tratamiento del TJE. Establece que se busca que "el ejercicio del derecho así reconocido no se vea obstaculizado ni en derecho ni de hecho" y enumera, no exhaustivamente, qué se considera como un obstáculo de derecho y de hecho al TJE:

[C]ualquier restricción a la adquisición y al transporte de materias primas y materias auxiliares, de energía y combustibles, así como de medios de producción y explotación de cualquier tipo, igualmente cualquier obstáculo a la venta y al transporte de los productos dentro y fuera del país y en el extranjero, así como cualquier otra medida que tuviere efecto análogo.

También resulta interesante cómo han ido evolucionando los textos de estos instrumentos. No es coincidencia que, por ejemplo, el TBI suizo difiera mucho más que los otros. Este fue suscrito en 1968, mientras que la mayoría fueron celebrados en los noven- 
$\operatorname{tas}^{80}$, siendo los TBIs suscritos con Finlandia, Italia y Suecia los únicos celebrados en el 2001. A pesar de las diferencias, una característica común en todos estos instrumentos internacionales es la presencia de cláusulas de nación más favorecida, las cuales tienen consecuencias prácticas muy importantes.

\subsection{Aplicación del derecho internacional y cláusulas de nación más favorecida}

Se ha mencionado el debate sobre si el TJE es un concepto o estándar autónomo, si es una referencia al estándar mínimo internacional, y si es posible tomar argumentos de otras ramas del derecho internacional. En la mayoría de TBIs ecuatorianos la redacción del TJE no hace referencia al derecho internacional, pero los TBIs suscrito con Estados Unidos, Francia y Venezuela sí lo hacen, y las consecuencias son de suma importancia.

Los tres TBIs atan al TJE de las inversiones al derecho internacional ${ }^{81}$. El TBI estadounidense explícitamente establece que las inversiones tendrán un TJE no menos favorable que el que exige el derecho internacional, mientras que el TBI francés incluso va más allá, y provee ejemplificativamente qué consultas se considerarían con un obstáculo al TJE. De esta forma, sin perjuicio de que deben seguirse las reglas de interpretación conforme a lo establecido en la Convención de Viena, todos los TBIs ecuatorianos deben ser leídos en conjunto para determinar cuál es el TJE que Ecuador está obligado a otorgar.

La referencia expresa a normas y principios del derecho internacional, el nivel mínimo exigible conforme al derecho internacional, y una lista no exhaustiva de conductas son de enorme ayuda al momento de interpretar al TJE como una obligación internacional. De esta forma, Ecuador expresamente ha

80. TBI Ecuador-Venezuela: 1993; TBI Ecuador-EEUU: 1993; TBI Ecuador-Argentina: 1994; TBI Ecuador-Francia: 1994; TBI Ecuador-China: 1994; TBI Ecuador-Reino Unido: 1994; TBI Ecuador-Bolivia: 1995; TBI Ecuador-Canadá: 1996; TBI Ecuador-España: 1996; TBI Ecuador-Países Bajos: 1999; TBI Ecuador-Perú: 1999.

81. El TBI venezolano menciona a las normas y principios del Derecho Internacional. 
previsto que debe aplicar normas de derecho internacional y, en consecuencia, independientemente de cuál sea su peso interpretativo, el estándar mínimo consuetudinario internacional es relevante al momento de interpretar el TJE previsto en un TBI ecuatoriano.

Finalmente, resulta importante notar que cláusulas de nación más favorecida (llamadas también cláusulas MFN, por sus siglas en inglés) están previstas en los TBIs ecuatorianos ${ }^{82}$. Estas en principio permitirían la aplicación de normas y principios de derecho internacional al TJE, sin limitarse únicamente a los TBIs que lo prevén expresamente, sino a todos los TBI ecuatorianos.

\section{El TJE EN los arbitrajes de inVERsión eCUATO- Rianos y la postura de la Procuraduría Gene- RAL DEL ESTADO Y DE LA CAITISA}

La interpretación del TJE no ha sido ajena en los casos en los que Ecuador ha sido parte. En este capítulo se repasará brevemente qué han mantenido algunos de los tribunales arbitrales de inversión, la posición de la Procuraduría General del Estado y de la CAITISA.

\subsection{EnCana Corporation c. Ecuador ${ }^{83}$}

En este caso EnCana alegaba que hubo una violación del TJE, garantizado en el TBI suscrito con Canadá. El Tribunal no encontró una violación al TJE, sin embargo, observó que podría haberse producido una violación si el Estado hubiera actuado de cierta forma. Indicó que un Estado debe actuar "con razonable coheren-

82. Véase, TBI Ecuador-Alemania. Art. 3(1); TBI Ecuador-Argentina. Art. 3(2); TBI Ecuador-Bolivia. Art. 3(2); TBI Ecuador-Canadá. Art. 2(3)(a)y(b), Art. 3 y Art. 4; TBI Ecuador-Chile. Art. 4(2); TBI Ecuador-China. Art. 3(2); TBI Ecuador-EEUU. Art. 2(1); TBI Ecuador-España. Art. 4; TBI EcuadorFrancia. Art. 5; TBI Ecuador-Finlandia. Art. 3; TBI Ecuador-Italia. Art. 3; TBI Ecuador-Países Bajos. Art. 3; TBI Ecuador-Perú. Art. 3; TBI Ecuador-Reino Unido. Art. 3; TBI Ecuador-Suecia. Art. 2 y 3; y, TBI Ecuador-Suiza. Art. 1.

83. EnCana Corporation c. Ecuador, Caso LCIA No. UN 3481, Laudo, 3/02/2006. 
cia y sin arbitrariedad en su tratamiento de las inversiones. Un brazo del Estado no puede afirmar lo que el otro niega en detrimento de un inversionista extranjero" ${ }^{\prime 4}$.

\subsection{Occidental Exploration c. Ecuador (Occidental I) ${ }^{85}$}

Para la interpretación del TJE, el Tribunal acudió al preámbulo del TBI y determinó que la estabilidad es un elemento esencial del TJE ${ }^{86}$. Señaló que en el caso particular, la ley tributaria fue cambiada sin ninguna claridad sobre su significado y extensión, y que la práctica y las regulaciones fueron inconsistentes con dichos cambios ${ }^{87}$. Consideró que Ecuador incumplió con estos requerimientos y que -siendo un tema objetivo- no depende si media o no buena fe.$^{88}$ En consecuencia, el Tribunal determinó que Ecuador incumplió con su obligación de otorgar un TJE bajo el artículo II(3)(a) del TBI y que deriva a su vez en una violación de protección y seguridad de la inversión ${ }^{89}$.

Adicionalmente, en cuanto a la referencia al derecho internacional en el TBI, el Tribunal concluyó que el estándar de TJE no es diferente del requerido bajo derecho internacional, que puede ser equiparado con este, y que el tratamiento por parte de Ecuador estuvo debajo de dicho estándar ${ }^{90}$.

\subsection{Occidental Exploration c. Ecuador (Occidental II) ${ }^{91}$}

Este Tribunal resolvió que Ecuador violó su obligación de otorgar un TJE, de conformidad con el artículo II(3)(a) del TBI

84. Ídem, párr. 158.

85. Occidental Exploration and Production Company c. Ecuador, Caso LCIA No. UN3467, Laudo Final, $1 / 07 / 2004$.

86. Ídem, párr. 183.

87. Ídem, párr. 184.

88. Ídem, párr. 186.

89. Ídem, párr. 187.

90. Ídem, párrs. 189-190.

91. Occidental Petroleum Corporation y Occidental Exploration and Production Company c. Ecuador, Caso CIADI No. ARB/06/11, Laudo, 5/10/2012. 
suscrito con Estados Unidos ${ }^{92}$. El Laudo fue parcialmente anulado ${ }^{93}$; sin embargo, se llevó a cabo un análisis respecto a la proporcionalidad respecto a la terminación, por medio de un Decreto de Caducidad dictado por el Ministro de Energía y Minas, de un Contrato de Participación entre OEPC y PetroEcuador para la exploración y explotación de hidrocarburos en el Bloque 15 de la Amazonía ecuatoriana.

El Tribunal resaltó que el principio de proporcionalidad es aplicado en varios foros internacionales (i.e. paneles de la OMC relativas al GATT, decisiones de la Corte Europea de Justicia, de la Corte Europea de Derechos Humanos, y de los tribunales sobre controversias internacionales de inversiones) ${ }^{94}$ y que, particularmente en arbitrajes CIADI, el principio es aplicado en violaciones de las obligaciones amparadas en TBIs, que incluyen el TJE ${ }^{95}$. Además, el Tribunal también determinó que la Ley $42^{96}$ violó el Contrato de Participación y que afectó las legítimas expectativas del inversionista y que, como resultado, es una violación del TJE previsto en el $\mathrm{TBI}^{97}$.

92. Véase, par. 452. It follows that even if OEPC, as the Tribunal found earlier, breached Clause 16.1 of the Participation Contract and was guilty of an actionable violation of Article 74.11 (or Articles 74.12 or 74.13), the Caducidad Decree was not a proportionate response in the particular circumstances, and the Tribunal so finds. The Caducidad Decree was accordingly issued in breach of Ecuadorian law, in breach of customary international law, and in violation of the Treaty. As to the latter, the Tribunal expressly finds that the Caducidad Decree constituted a failure by the Respondent to honour its Article II.3(a) obligation to accord fair and equitable treatment to the Claimants' investment, and to accord them treatment no less than that required by international law.

93. Véase, Occidental Petroleum Corporation y Occidental Exploration and Production Company c. Ecuador, Caso CIADI No. ARB/06/11, Decisión sobre anulación del laudo, 2/11/2015, párr. 583: El Comité ha concluido que el Tribunal se extralimitó manifiestamente en sus facultades al asumir erróneamente competencia respecto de la inversión cuyo titular beneficiario es ahora el inversor chino Andes, con el resultado de que la compensación debida a las Demandantes debe reducirse del $100 \%$ al $60 \%$ del valor del Bloque 15.

94. Occidental II, párrs. 402-403.

95. Ídem, párr. 404. Se hace referencia a los siguientes casos: MTD Equity SDN.BHD y otro c. Chile, CIADI Caso No. ARB/01/7, 25/05/2004; LG\&E Energy Corp. y otros c. Argentina, CIADI Caso No. ARB/02/1, 3/10/2006; Tecmed S.A. c. México, CIADI Caso No. ARB (AF)/00/2, 29/05/2003; y, Azurix Corp. c. Argentina, CIADI Caso No. ARB/01/12, 14/07/2006.

96. Ley de Modificación de la Ley de Hidrocarburos del Ecuador, RO 25/04/2006. Con esta ley se incorporó una reforma, la cual permitiría la participación del Estado en los excedentes de los precios de venta de petróleo no pactados o no previstos. Primero, esta participación sería del $50 \%$ y posteriormente del $99 \%$.

97. Occidental II, párr. 527. 


\subsection{Duke Energy c. Ecuador ${ }^{98}$}

El Tribunal analizó si el estándar previsto en el TBI es autónomo o si se limita a reflejar disposiciones del derecho internacional consuetudinario. Señaló que en el caso "la discusión sobre el carácter autónomo del estándar es irrelevante y parece haber sido superada por la evolución que reflejan las más recientes decisiones del CIADI" ${ }^{\prime \prime 99} \mathrm{y}$, siguiendo lo resuelto en los casos Azurix y CMS, el Tribunal consideró que "los estándares son esencialmente idénticos" ${ }^{\prime 100}$.

Coincidiendo con los tribunales de CMS, Tecmed, Occidental y LG\&E ${ }^{101}$, consideró que "un entorno jurídico y económico estable y previsible debe considerarse como elemento esencial del estándar del trato justo y equitativo", que la estabilidad del entorno jurídico y económico está directamente vinculada a las expectativas justificadas del inversionista y que para que puedan estar protegidas, "las expectativas del inversionista deben ser legítimas y razonables en el momento en que el inversionista efectúa la inversión"102.

\subsection{M.C.I. c. Ecuador ${ }^{103}$}

El Tribunal mantuvo que al revocar el permiso de una compañía "no surge elemento alguno que justifique calificar esa medida como violatoria per se del trato justo y equitativo ni que constituya una expropiación de conformidad con el TBI"104.

En cuanto a las legítimas expectativas que inversionista podría invocar como violatorias de un TJE, el Tribunal consideró

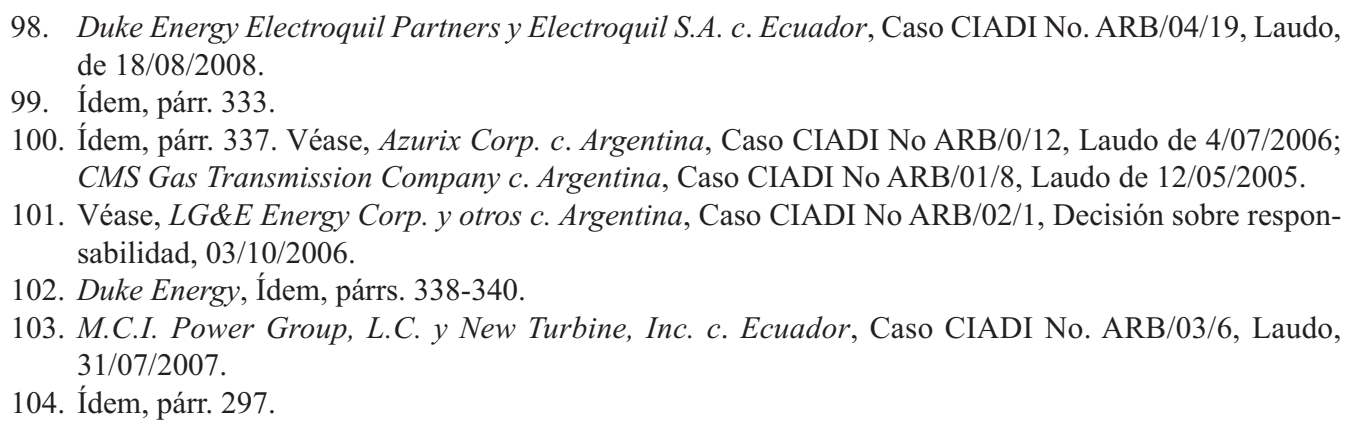

98. Duke Energy Electroquil Partners y Electroquil S.A. c. Ecuador, Caso CIADI No. ARB/04/19, Laudo, de 18/08/2008.

99. Ídem, párr. 333 .

100. Ídem, párr. 337. Véase, Azurix Corp. c. Argentina, Caso CIADI No ARB/0/12, Laudo de 4/07/2006; CMS Gas Transmission Company c. Argentina, Caso CIADI No ARB/01/8, Laudo de 12/05/2005.

101. Véase, $L G \& E$ Energy Corp. y otros c. Argentina, Caso CIADI No ARB/02/1, Decisión sobre responsabilidad, 03/10/2006.

102. Duke Energy, Ídem, párrs. 338-340.

103. M.C.I. Power Group, L.C. y New Turbine, Inc. c. Ecuador, Caso CIADI No. ARB/03/6, Laudo, $31 / 07 / 2007$.

104. Ídem, párr. 297. 
que no es relevante el desconocimiento del inversionista del derecho local ${ }^{105}$. Adicionalmente, el Tribunal sostuvo que:

[E]l trato justo y equitativo obliga convencionalmente a los Estados parte del TBI a respetar los estándares de tratamiento requeridos por el derecho internacional. El derecho internacional mencionado por el Artículo II del TBI se refiere al derecho internacional consuetudinario, es decir a la práctica reiterada, general y constante de los Estados respetada por éstos con conciencia de su obligatoriedad. El trato justo y equitativo es entonces la expresión de una norma de derecho. Un trato injusto o inequitativo, al igual que un trato arbitrario, es aquel al que el Tribunal podrá razonablemente reconocer como un acto contrario a derecho ${ }^{106}$.

El Tribunal también precisó que el TJE "no puede confundirse con la aplicación de la regla ex aequo et bono" ${ }^{107}$, y diferenció al hostigamiento por parte del Estado, de una actitud inamistosa, siendo esta última una circunstancia que no configura un "trato injusto o inequitativo, discriminatorio o arbitrario en violación de los parámetros establecidos por el derecho internacional receptados en el TBI"108.

\subsection{Murphy Exploration c. Ecuador (Murphy II) ${ }^{109}$}

El Tribunal analizó si el artículo II(3)(a) del TBI suscrito con Estados Unidos representa un estándar autónomo, distinto del estándar establecido por el derecho internacional consuetudinario. El Tribunal señaló que el debate es más teórico que sustancial, pero que es claro que el TJE refleja componentes como: transparencia, consistencia, estabilidad, predictibilidad, buena

\footnotetext{
105. Ídem, párr. 303: "Dentro de las expectativas legítimas que Seacoast podría invocar como violatorias de un trato justo y equitativo y de buena fe, el Tribunal no puede considerar como relevante la mera invocación del desconocimiento de los efectos legales de la revocatoria o de la existencia de un recurso para impugnarla."

106. Ídem, párr. 369.

107. Ídem, párr. 370.

108. Ídem, párr. 371.

109. Murphy Exploration and Production Company International c. Ecuador [II], Caso PCA No. 2012-16 (antes AA 434), Laudo final parcial, de 06/05/2016.
} 
fe, y cumplimiento de las legítimas expectativas del inversionista $^{110}$. El Tribunal indicó que la aplicación de estos componentes dependerá del caso en particular y que la función de una cláusula de TJE es asegurar estabilidad y predictibilidad, y -siguiendo a Occidental I- señala que es un requisito objetivo ${ }^{111}$. Añadió que el proteger dicha estabilidad y predictibilidad también sustenta el estándar moderno internacional consuetudinario $^{112}$, que el estándar mínimo internacional y el estándar en el TBI continúan influenciándose entre ellos y que el Tribunal los mira cada vez más alineados ${ }^{113}$.

Adicionalmente, el Tribunal -aunque nota que algunos tribunales fueron muy lejos al decir que los estándares son esencialmente lo mismo- ${ }^{114}$ indicó que no encontró una diferencia material entre el estándar internacional consuetudinario y el estándar de TJE del TBI, que ciertamente el TJE del TBI no es más bajo que el estándar mínimo internacional, y que no encontró necesario determinar para los propósitos del caso si el estándar de TJE refleja un estándar autónomo sobre el estándar consuetudinario internacional ${ }^{115}$.

En cuanto a las legítimas expectativas del inversionista, el Tribunal expresamente estableció que la obligación de otorgar un TJE requiere que el Estado las proteja ${ }^{116}$, y que estas están basadas en el conocimiento objetivo del marco legal sobre el cual se realizó la inversión ${ }^{117}$. También, el Tribunal observó que los Estados cuentan con flexibilidad para responder a circunstancias cambiantes, a menos que hayan estabilizado su relación con un inversor ${ }^{118}$.

110. Ídem, párr. 206.

111. Ídem, el Tribunal señaló que: “(...) Notwithstanding, the function of the FET clause in investment treaties is broadly the same: it ensures the stability and predictability of the legal and business framework in the State party subject to any qualifications otherwise established by the treaty and under international law."

112. Ídem, párr. 207: "Protecting the stability and predictability of the host State's legal and business framework also underpins the modern customary international law standard."

113. Ídem, párr. 208.

114. Ídem. Véase, Duke Energy Laudo, párr. 337; Occidental I Laudo, párr. 190.

115. Ídem, párr. 208.

116. Ídem, párr. 247.

117. Ídem, párr. 248.

118. Ídem, párr. 276. Véase, párrs. 280-282. "[T]he Tribunal does not consider that the enactment of Law 42 at 50\% breached Claimant's legitimate expectations and thus finds that it did not breach the FET 


\subsection{Perenco Ecuador Limited c. Ecuador ${ }^{119}$}

El caso todavía está activo, pero el Tribunal ya realizó un análisis del TJE previsto en el TBI suscrito con Francia. Señaló que la "formulación particular del estándar no esta relacionada con el estándar internacional mínimo de trato en virtud del derecho internacional consuetudinario"120 e hizo referencia al caso Waste Management ${ }^{121}$ y también analizó las expectativas razonables del inversionista como un elemento del TJE, para lo cual notó que es necesario hacer una determinación objetiva de estas expectativas, considerando sus circunstancias ${ }^{122}$.

El Tribunal consideró que la Ley 42 per se no representaba un incumplimiento del artículo 4 del TBI, pero que, al avanzar del $50 \%$ al 99\% sí constituyó una violación. ${ }^{123}$ Es ilustrativo mencionar que en el caso de Burlington, el cual parte de hechos muy similares, el Tribunal de este caso resolvió que no tenía jurisdicción sobre el reclamo de Burlington por falta de trato justo y equitativo bajo el artículo II(3)(a) del Tratado suscrito con Estados Unidos ${ }^{124}$,

standard of the Treaty. (...) The enactment of Law 42 at $99 \%$ ran afoul of the above-mentioned clauses in the Participation Contract and the domestic legal regime, as well as the promise under Article II(3)(a) of the Treaty to accord Claimant's investment fair and equitable treatment."

119. Perenco Ecuador Limited c. Ecuador, Caso CIADI No. ARB/08/6, Decisión sobre las cuestiones pendientes relativas a la jurisdicción y sobre la responsabilidad, 12/09/2014.

120. Ídem, párr. 557.

121. Ídem, párr. 558: "Con eso dicho, como han decidido muchos otros tribunales de tratados de inversión enfrentados con la tarea de determinar el significado de un estándar - incluso donde el tratado aplicable no contiene referencia alguna al derecho internacional consuetudinario-, hay mucho que decir por el enfoque general establecido por el tribunal en Waste Management, Inc. c. Estados Unidos Mexicanos, que entendió que la conducta atribuible al Estado y perjudicial para el inversor viola el estándar cuando sea: "[...] arbitraria, notoriamente injusta, antijurídica o idiosincrática, y discriminatoria si la demandante es objeto de prejuicios raciales o regionales o si involucra ausencia de debido proceso que lleva a un resultado que ofende la discrecionalidad judicial, como podría ocurrir con un fracaso manifiesto de la justicia natural en los procedimientos judiciales o una falta total de transparencia e imparcialidad en un proceso administrativo". Véase, Waste Management, Inc. c. Estados Unidos Mexicanos, Caso CIADI No. ARB (FA)/00/3, Laudo, 30/04/2004, párr. 98.

122. Ídem, párr. 560.

123. Ídem, párrs. 601-606, 627.

124. Véase, Perenco Ecuador Limited c. Ecuador, Caso CIADI No. ARB/08/6, Decisión sobre jurisdicción, 2/06/2010. Véase, párr. 204. No obstante, fuera del contexto de la cláusula paraguas, una violación del contrato por parte del Estado puede equivaler a una violación del Tratado sólo si el Estado ejerce poder soberano (Duke Energy, párr. 345). Expresado de otro modo, la presunta repudiación de las cláusulas de indemnización impositivas por parte de la Demandada podrían resultar en una violación por falta de trato justo y equitativo bajo el Tratado sólo si la Demandada hubiese ejercido su poder soberano. El Tribunal, sin embargo, ya determinó que las cláusulas de indemnización impositivas no acarrean el ejercicio de poder soberano. Por lo tanto, este reclamo no satisface el relevante estándar prima facie porque los hechos alegados, aun si fuesen probados, no podrían constituir una violación por parte de 
pero -al analizar la expropiación- consideró que la Ley 42 al 99\% no privó sustancialmente a Burlington del valor de su inversión, y que no puede haber expropiación en ausencia de una privación sustancial $^{125}$.

De los casos revisados, y de la información pública disponible, es evidente que el TBI más litigado es el suscrito con Estados Unidos. Sin embargo, todavía están pendientes de ser resueltos varios arbitrajes de inversión, en los que seguramente el TJE tendrá un papel importante ${ }^{126}$. Como se puede observar, no ha sido superado el debate sobre el alcance y naturaleza del TJE. Todavía no existe uniformidad sobre su relación con el estándar mínimo internacional (i.e. si es un estándar autónomo, no diferente, esencialmente idéntico, etc.) pero, a pesar de las diferencias, es posible identificar elementos comunes del TJE.

Si bien lo determinado por un tribunal de inversión no es precedente vinculante para otro, la constante referencia a lo resuelto en otros casos es evidente y poco a poco se han ido determinando estos elementos. De los casos revisados, los tribunales han considerado los siguientes como componentes del TJE:

- Coherencia y no arbitrariedad o inconsistencia (EnCana, Occidental I)

- Estabilidad y previsibilidad o predictibilidad (Duke Energy, Murphy II)

la Demandada de su obligación bajo el Tratado de acordar a la Demandante trato justo y equitativo. En consecuencia, el Tribunal no tiene jurisdicción sobre este reclamo.

125. Véase, Burlington Resources c. Ecuador, Caso CIADI No. ARB 08/5, Decisión sobre Responsabilidad, 14/12/2012, párr. 456. Véase, Procuraduría General del Estado. Visión Crítica del Arbitraje de Inversiones Desde la Experiencia del Ecuador. (Quito: Procuraduría General del Estado, 2016), «http://www.pge.gob.ec/index.php/component/content/article?id=590», pp. 132-9.

126. Véase, Chevron Corporation y Texaco Petroleum Company c. Ecuador, Corte Permanente de Arbitraje, Caso No. 2009-23 (Chevron II). En Chevron II (llamado Chevron III por la Procuraduría General del Estado), Chevron y Texaco alegan, inter alia, la violación por parte de Ecuador del trato justo equitativo, amparado por el TBI suscrito con Estados Unidos, y adicionalmente se discute su reclamo de denegación de justicia. Sin duda, la resolución de este caso será de mucha importancia para el estudio y desarrollo del trato justo y equitativo. Véase, C. Muriel Bedoya, Chevron and the Ecuadorian Torpedo, Cambridge International Law Journal, 22/12/2016, «http://cilj.co.uk/2016/12/22/chevron-and-the-ecuadorian-torpedo/». 
- Objetividad del estándar (Occidental I, Murphy II, Perenco)

- Proporcionalidad (Occidental II)

- Transparencia (Murphy II)

- Buena Fe (Murphy II)

- Expectativas legítimas del inversionista (Occidental II, Duke Energy, M.C.I., Murphy II, Perenco)

Cada tribunal ha realizado precisiones de acuerdo al caso en concreto, pero se evidencian importantes precisiones o consideraciones. Por ejemplo, la referencia al preámbulo del TBI (Occidental I) y a lo resuelto en otros foros internacionales (Occidental II); la no confusión del TJE con la aplicación de la regla ex aequo et bono (M.C.I.); el exigir que las legítimas expectativas sean razonables (Duke Energy), que estas suponen el conocimiento objetivo del marco legal del Estado (Murphy II) y que resulta irrelevante el desconocimiento del derecho local por parte del inversionista (M.C.I.); o, que los Estados cuentan con flexibilidad para adaptarse a cambios (Murphy II). Sin perjuicio de que cada caso tiene sus particularidades, sería razonable concluir que -en palabras del Tribunal de Murphy II- el TJE previsto en los TBIs no es más bajo que el estándar mínimo internacional y que estos se encuentran cada vez más alineados.

\subsection{Postura de la Procuraduría General del Estado}

La Procuraduría General del Estado ecuatoriano (PGE) realizó un análisis del sistema, y presentó sus críticas y propues$\operatorname{tas}^{127}$. La PGE señala que desde el año 2004, Ecuador ha enfrentado 28 arbitrajes de inversión, 18 concluidos y 10 acti$\operatorname{vos}^{128}$. Respecto al TJE, la PGE sugiere que "la tendencia es definir

127. Procuraduría General del Estado. Visión Crítica del Arbitraje de Inversiones Desde la Experiencia del Ecuador. (Quito: Procuraduría General del Estado, 2016), «http://www.pge.gob.ec/index.php/component/content/article?id=590».

128. Ídem, pp. 18-99. La PGE realiza el siguiente detalle de los arbitrajes de inversión en los que Ecuador es parte. Casos terminados: Encana Terminado Favorable 14/03/03-03/02/06; OXY I Terminado Parcialmente Favorable 11/11/02-04/07/07; IBM Terminado Solución Amistosa 06/09/02-22/07/04; Unete Terminado Solución Amistosa 10/06/09-12/06/13; Quiport Terminado Solución Amistosa 12/08/0911/11/11; Machala Power Terminado Solución Amistosa 17/03/05-20/05/09; City Oriente Terminado Solución Amistosa 10/10/06-12/09/08; Repsol II Terminado Solución Amistosa 05/10/01-08/01/07; Ulysseas Terminado Favorable 08/05/09-12/06/12; Murphy I Terminado Favorable 15/04/08-15/12/10; 
de manera precisa los términos llegando incluso al detalle"129 y hace énfasis en que:

[L]os textos de los AII [Acuerdos Internacionales de Inversión] deben ser más claros y detallados, estableciendo cuándo y bajo qué circunstancias se genera una responsabilidad para los Estados partes que pueda ser atribuida por un Tribunal bajo el amparo de un tratado ${ }^{130}$.

Además, considera que deberían tomarse las siguientes medidas ${ }^{131}$ :

- Dependiendo del estándar del que se trate, debería establecerse claramente quién de (sic) la prueba y el valor que deben darse a las resoluciones administrativas o judiciales del Estado demandado.

- Incluir listas taxativas de las obligaciones de los Estados receptores de la inversión para cada uno de los estándares.

- Incluir las obligaciones que deben cumplir los inversionistas para poder alegar la protección de un determinado estándar.

- Incluir la forma de reparación que deberá ser aplicada cuando se viole cada estándar.

- Detallar qué actos y de qué instituciones o dependencias públicas generan responsabilidad internacional del Estado.

- Incluir una lista exhaustiva de los sectores o aspectos que el Estado excluye de la protección.

La PGE propone que "la solución podría estar precisamente en la aplicación de "reglas" y no de estándares ya que las primeras ofrecen mayores certezas y uniformidad en su práctica frente

Murphy II Terminado Favorable 30/12/10-19/08/11; MCI Terminado Favorable 16/12/02-19/10/09; Emelec Terminado Favorable 13/12/04-02/06/09; Técnicas Reunidas S.A. Terminado Desistimiento 31/10/06-13/05/08; Chevron II Terminado Desfavorable 21/12/06-26/09/14 (se refiere al Caso No. 2007-02/AA277 de la Corte Permanente de Arbitraje); TBI Ecuador - EUA Terminado Desfavorable 28/06/11-29/09/12; OXY II Terminado Parcialmente Favorable 17/05/06-02/11/15; Duke Energy Terminado Parcialmente Favorable 30/08/04-18/08/08. Casos activos: Merck Sharp \& Dohme: 29/11/11; RSM Company: 13/05/10; COPPER MESA: 21/01/11; Zamora Gold: 11/07/11; Chevron III: 09/10/07 (se refiere al Caso No. 2009-23 de la Corte Permanente de Arbitraje,); Burlington: 21/04/08; Perenco: 30/04/08; Murphy III: 30/09/11; GLP: 01/07/15; ALBACORA: 04/04/16.

129. Ídem, p. 49.

130. Ídem, p. 68.

131. Ídem. 
a los límites de los estándares de protección de inversiones" e indica que "[p]arece ser hora de probar con elementos del sistema civilista ya que las figuras del common law han sido poco efectivas en materia de inversiones"132. Refiriéndose al TJE, señala que "[n]o existe un consenso sobre si el lenguaje de TJE incorporado en la mayoría de TBI abarca las normas del derecho internacional consuetudinario sobre el estándar mínimo internacional de trato a nacionales de otros Estados"133 y resume las obligaciones derivadas del TJE determinadas por los tribunales ${ }^{134}$.

(i) La obligación del Estado de otorgar estabilidad y protección de las legítimas expectativas del inversionista.

(ii) Obligación de transparencia.

(iii) Obligación de cumplimiento de obligaciones contractuales (que no se debe confundir con la cláusula paraguas de un TBI).

(iv) Garantía de acceso a la justicia y prohibición de denegación de justicia.

(v) Garantía de acceso a medios eficaces para entablar reclamos y ejercitar derechos.

(vi) No arbitrariedad.

(vii) Proporcionalidad.

La PGE aclara que esto no significa "en el futuro no se añadan más obligaciones o su contenido se haga aún más extensivo", pero indica que "[l]o único que podría llegar a impedir esto sería una reforma al sistema de protección de inversiones que puede poner un límite a estas interpretaciones amplias y extensivas"135. La PGE concluye que los instrumentos internacionales relativos a inversiones, incluyendo los ecuatorianos, "son laxos y no incluyen una definición o delimitación del TJE" y que "la interpretación más ponderada, a la luz del objetivo general de estos

132. Ídem, p. 100. De hecho, evidencia empírica sugeriría que, en materia de protección de inversiones, un sistema de common law podría ser superior a un sistema de civil law. Véase, R. LA PORTA, F. LoPEZDE-SiLANES, y A. ShLEIFER. "Law and Finance After a Decade of Research", en George M. ConstANTINIDES (Ed.), et al, Handbook of the Economics of Finance, vol. 2, Chapter 6, pp. 425-491, ELSEVIER, 2013.

133. Ídem, p. 102.

134. Ídem, pp. 102-103.

135. Ibídem. 
instrumentos internaciones, debería ser, acogiendo las palabras del tribunal del caso Mondev c. EE.UU., el de proveer un grado de protección significativo"136.

Finalmente, la PGE considera que el TJE "no es un estándar más alto que el de trato en el derecho internacional consuetudinario"137, que este "no significa que el TBI sea una póliza de seguro contra los cambios en el marco jurídico y regulatorio del Estado receptor"138, y que "[e]l alto límite de este estándar asigna al inversionista la responsabilidad de proceder "con conocimiento de la situación regulatoria", lo cual es un requisito indispensable para un inversionista que desea instalarse en un determinado país"139.

\subsection{Postura de la CAITISA y Denuncia de los TBIs}

A principios de mayo de 2017, la CAITISA finalmente emitió su informe respecto a los tratados de protección recíproca de inversiones y al sistema de arbitraje en materia de inversiones ${ }^{140}$. En este se recogen varias críticas y recomendaciones.

Principalmente, la CAITISA recomendó concluir el proceso de denuncia de los TBIs, la negociación de nuevos instrumentos entre el Estado e inversionistas privados (como la celebración de contratos internacionales de inversión con derechos restringidos y obligaciones para los inversionistas), planteó también los principales lineamientos para un modelo alternativo de tratado de inversión, la inclusión de ciertos derechos del Estado y obligaciones para los inversionistas, y la exclusión de ciertos "privilegios".

136. Ídem, p. 106.

137. Ibídem.

138. Ídem, p. 107.

139. Ibídem.

140. Comisión para la Auditoría Integral Ciudadana de los Tratados de Protección Recíproca de Inversiones y del Sistema de Arbitraje en Materia de Inversiones. Informe Ejecutivo: Auditoría integral ciudadana de los tratados de protección recíproca de inversiones y del sistema de arbitraje en materia de inversiones en Ecuador. (Quito: CAITISA, 2017), «http://http://www.caitisa.org/index.php/home/enlacesde-interes». 
Además, entre sus recomendaciones están la exclusión de la cláusula de solución de disputas inversionista-estado de los TBIs, apoyar la creación de una corte permanente internacional para la solución de controversias entre inversionistas y estados, y la creación de un observatorio internacional sobre inversiones y empresas transnacionales ${ }^{141}$.

En cuanto al TJE, la CAITISA señaló que:

(...) la expresión "trato justo y equitativo", en sí misma, es indeterminada, ambigua y puede estar sujeta a diversas interpretaciones. Varios tribunales arbitrales han interpretado extensivamente el concepto de justo y equitativo, al inducir nociones como las legítimas expectativas del inversor, las cuales no están contemplados en los ordenamientos jurídicos internacionales, lo que da lugar a que estas interpretaciones sobrepasen los estándares internacionales de trato a la inversión, reconocidos mundialmente $(\ldots)^{142}$.

Adicionalmente, recomendó "excluir o replantear en cualquier tratado futuro sobre inversiones" la cláusula de TJE. La Comisión señaló que:

Esta cláusula tiene como propósito llenar vacíos con otras normas más específicas, con el fin de obtener, potencialmente, un mayor nivel de protección al inversionista de aquel que establece el tratado, por lo cual se debe definir de forma estricta su alcance, de manera que impida interpretaciones que se ajusten a las expectativas del inversionista como criterio para fijar parámetros de responsabilidad internacional del Estado $^{143}$.

En cuanto a la terminación de los TBIs, dado cómo se llevaron los procedimientos de denuncia, parecía ser que para Ecuador todos los TBIs eran iguales, pero algunos TBIs eran más iguales que otros ${ }^{144}$, puesto que los procedimientos de denuncia en unos

141. Ídem, pp. 99-108.

142. Ídem, p 18.

143. Ídem, p. 103.

144. Véase, C. Muriel Bedoya, Of BITs, Demons and Tremors: Foreign Investment in Ecuador, Young ICCA Blog, 28/07/2016, «goo.gl/DnfsmT». 
casos avanzaron más que otros. No obstante, tal como se lo mencionó anteriormente, la recomendación de la CAITISA de denunciar todos los TBIs fue acogida poco después por el ex Presidente Correa.

Ahora, para que tenga lugar la terminación de los TBIs se deberá cumplir con las propias normas de dichos instrumentos y las de derecho internacional que les sean aplicables (i.e. las de la Convención de Viena Sobre el Derecho de los Tratados) ${ }^{145}$. Mientras tanto, hasta que se hagan efectivas las denuncias de los TBIs $\mathrm{y}$, posteriormente, hasta que concluyan los periodos de supervivencia de cada TBI, sus normas continuarán aplicando.

Sin perjuicio de los procedimientos formales que deben seguirse para la denuncia de los TBIs -y los que debieron haberse seguido- o si las denuncias estuvieron fundamentadas o no en falacias ${ }^{146}$, lo cierto es que los siguientes pasos que tome el Ecuador serán decisivos para la atracción de inversión extranjera y para su imagen y relaciones internacionales.

\section{CONCLUSIÓN}

Sin duda, la obligación de otorgar un trato justo y equitativo a la inversión extranjera está expresamente reconocida por la República del Ecuador. El estándar se encuentra recogido en los tratados bilaterales de inversión suscritos por Ecuador, aunque su definición, elementos y alcance no están completamente determinados. A pesar de ello, los tribunales internacionales han identificado algunas de sus características con cierta uniformidad y si bien no existe consenso respecto a su relación con el estándar mínimo internacional, estos están alineados (o al menos alineándose), y su desarrollo está en progreso.

145. Véase, Convención de Viena, Parte V, N. 31.

146. Véase, J. Jaramillo y C. Muriel Bedoya, Ecuadorian BITs'Termination Revisited: Behind the Scenes, Kluwer Arbitration Blog, 26/05/2017, «https://goo.gl/Sn82xd ». 
$\mathrm{Al}$ interpretar el trato justo y equitativo, los tribunales han acogido las reglas de interpretación previstas en la Convención de Viena, y la costumbre internacional puede ser admisible y relevante. El estándar mínimo internacional puede reflejarse en reglas de instrumentos internacionales, como por ejemplo los que regulan al trato justo y equitativo, y este es independiente del trato otorgado por un Estado en su territorio. Además, sin perjuicio de las discusiones sobre su aplicación en las disputas Inversionista-Estado, es evidente que el estándar hasta cierto punto limita la actuación de un Estado, y otorga garantías a los inversionistas. En consecuencia, debe ser analizado objetivamente.

La falta de definición del estándar no es necesariamente una desventaja, toda vez que en esta imprecisión se encuentra su flexibilidad y capacidad de adaptación. No es claro si funcionarían listas taxativas de las obligaciones de los Estados receptores de la inversión o un detalle exhaustivo de qué actos y de qué instituciones o dependencias públicas generan responsabilidad internacional del Estado. Todo contrato es incompleto y los acuerdos bilaterales de inversión no son la excepción. El limitar un estándar a un número específico de conductas restringe a su vez su desarrollo y adaptabilidad a nuevas circunstancias. Es posible, como lo manifiesta la PGE, añadir más obligaciones o extender su contenido en el futuro, pero dada la complejidad y poca celeridad de las negociaciones y formalidades que deben seguir los instrumentos internacionales, esta opción es igual de deseable que una absoluta indeterminación.

Finalmente, es importante tener presente la posición del Estado respecto al régimen de inversiones para determinar cuáles serán los desafíos de las futuras negociaciones. Ecuador debe ser parte del desarrollo del sistema y no aislarse de esta tarea. Empezar por mejorar el sistema de administración de justicia es un primer paso, ya que de poco o nada sirve garantizar incentivos $u$ otorgar ciertos estándares a los inversionistas bajo derecho local si estos no van a ser respetados ${ }^{147}$.

147. Véase, C. Muriel Bedoya, Constitutional Review of Arbitral Awards: Between Protectionism and Interventionism, Kluwer Arbitration Blog, 05/03/2015, «http://goo.gl/hbFg3o»; y, C. MuRIEL BedoyA, 
Ciertamente, el sistema tiene imperfecciones, pero tampoco es claro si la denuncia de todos los instrumentos internacionales relativos a inversiones haya sido la medida adecuada. El TJE, por su parte, es un estándar que sigue siendo muy importante en el derecho internacional y en el arbitraje internacional de inversiones. El TJE continúa en desarrollo y seguramente será objeto de debate en las futuras negociaciones que lleve la República del Ecuador. Una definición muy estricta y exhaustiva, sin embargo, podría no ser lo más recomendable para su evolución, sino todo lo contrario.

“Control constitucional en el sistema arbitral ecuatoriano: ¿Garantismo o Intervencionismo?”, Revista Ecuatoriana de Arbitraje, No. 7, 2015, pp. 203-228. 
Camilo Muriel Bedoya

\begin{tabular}{|c|c|c|c|}
\hline 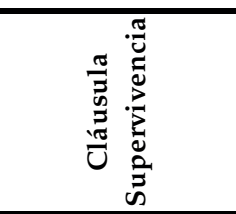 & 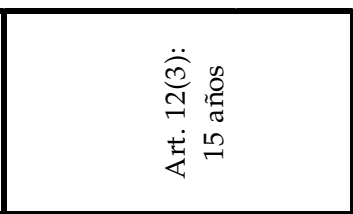 & 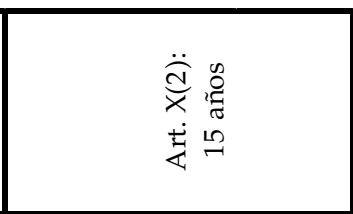 & 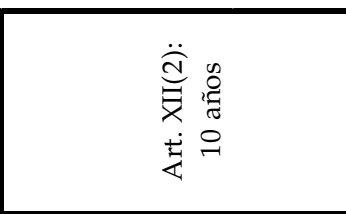 \\
\hline 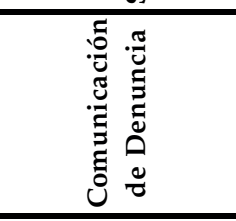 & 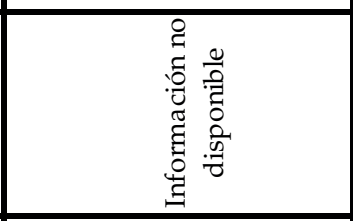 & 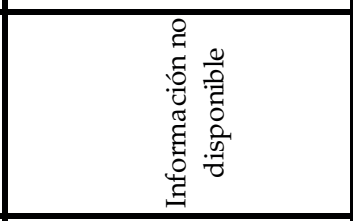 & 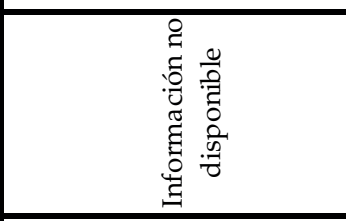 \\
\hline 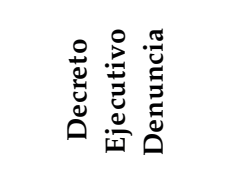 & 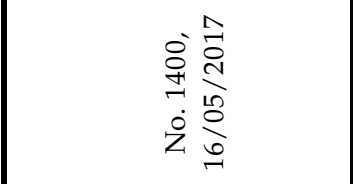 & 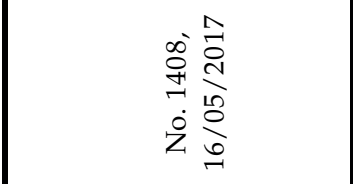 & 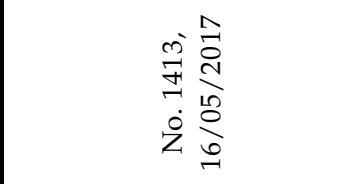 \\
\hline 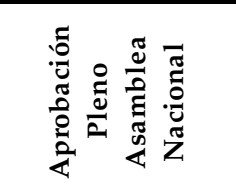 & 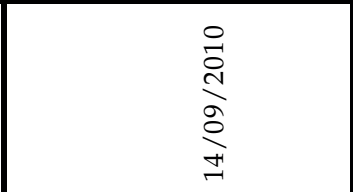 & 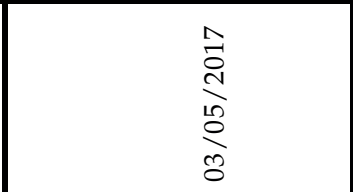 & 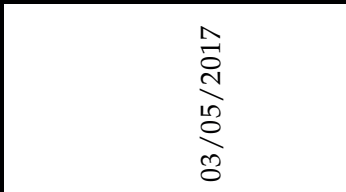 \\
\hline 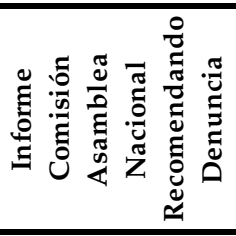 & 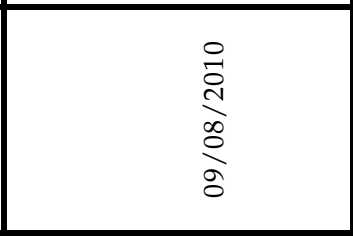 & 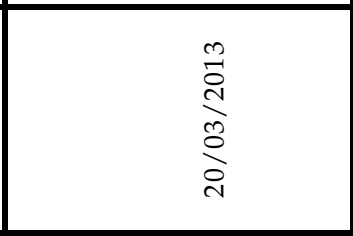 & 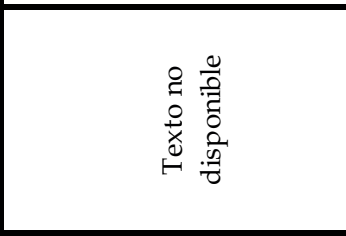 \\
\hline 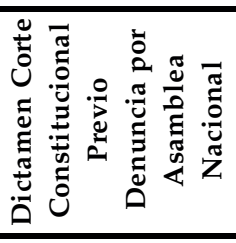 & 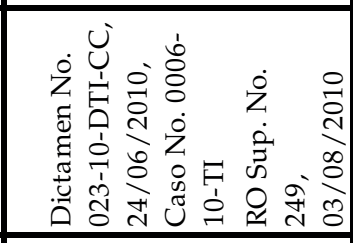 & 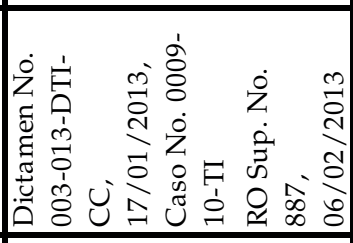 & 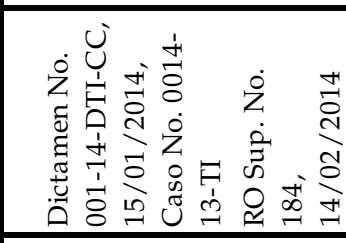 \\
\hline 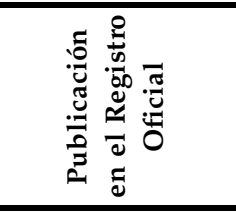 & 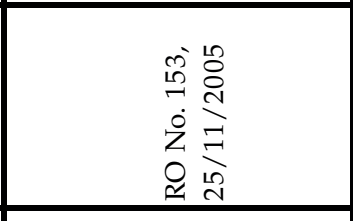 & 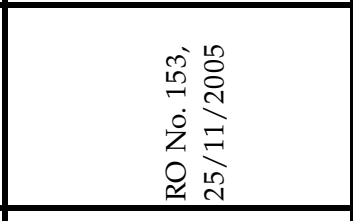 & 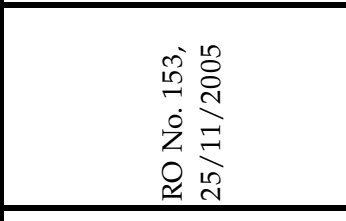 \\
\hline 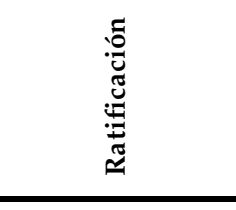 & 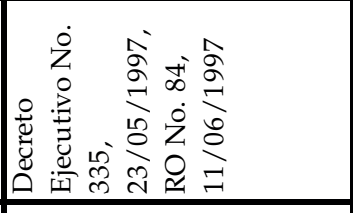 & 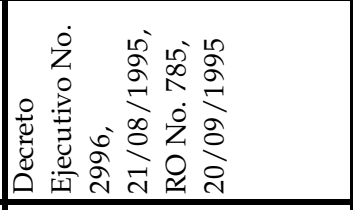 & 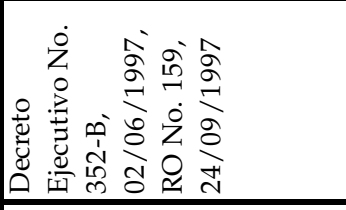 \\
\hline 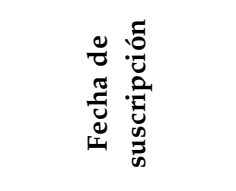 & 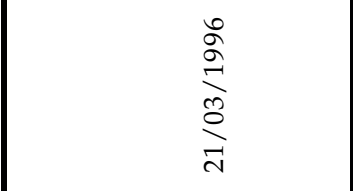 & 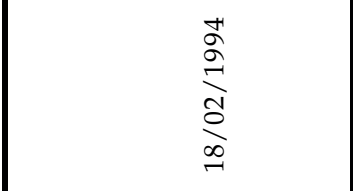 & $\begin{array}{l}\stackrel{2}{\sigma} \\
\stackrel{2}{2} \\
\stackrel{2}{2} \\
\stackrel{2}{1}\end{array}$ \\
\hline$\overline{\hat{\theta}}$ & 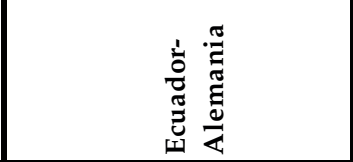 & 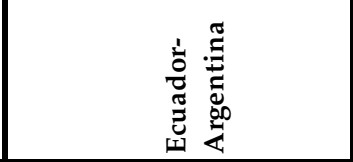 & 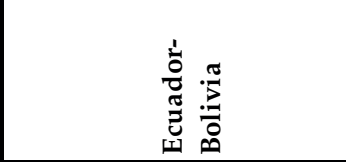 \\
\hline
\end{tabular}


El trato justo y equitativo en los tratados de protección recíproca de inversiones ecuatorianos

\begin{tabular}{|c|c|c|c|}
\hline 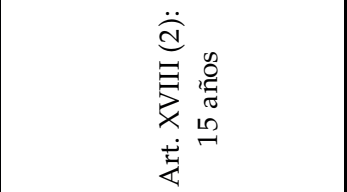 & 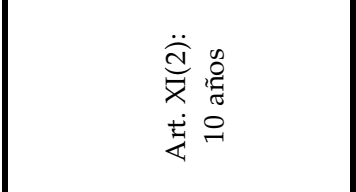 & 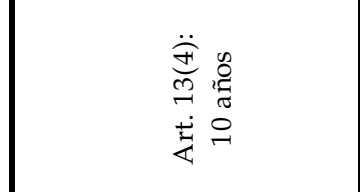 & 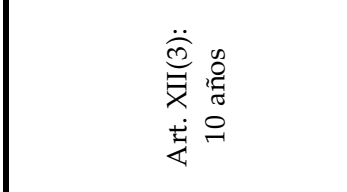 \\
\hline 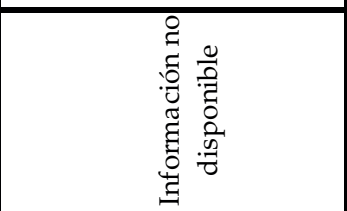 & 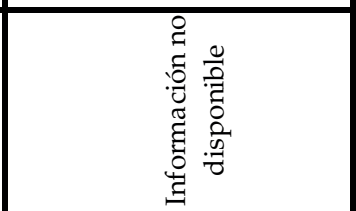 & 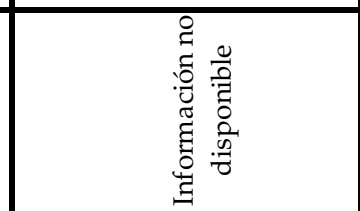 & 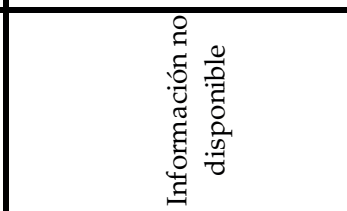 \\
\hline 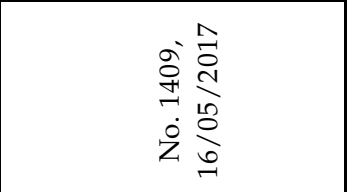 & 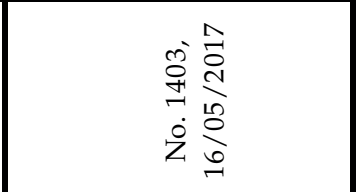 & 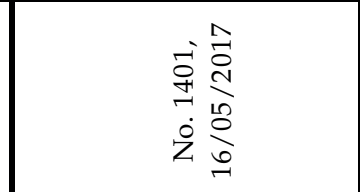 & 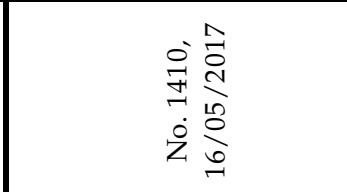 \\
\hline 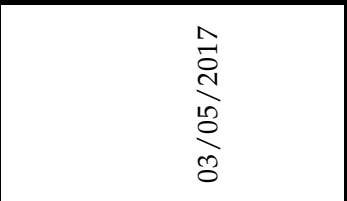 & 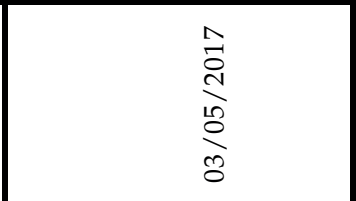 & 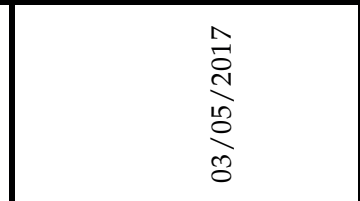 & 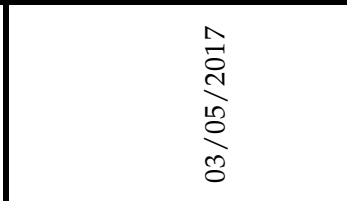 \\
\hline 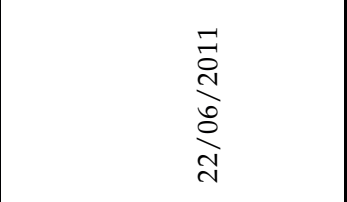 & $\begin{array}{l}\vec{c} \\
\stackrel{0}{1} \\
\stackrel{2}{0} \\
\stackrel{2}{2}\end{array}$ & $\underset{\substack{0 \\
\stackrel{1}{0}}}{\stackrel{0}{+}}$ & 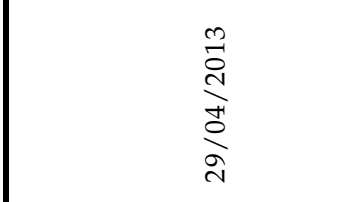 \\
\hline 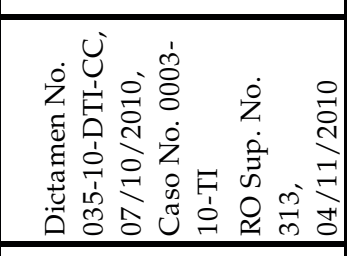 & 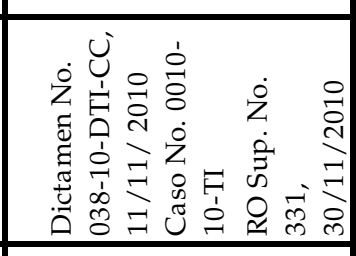 & 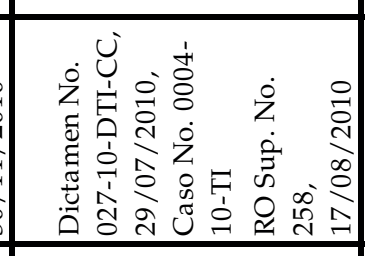 & 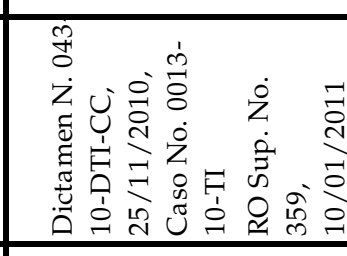 \\
\hline 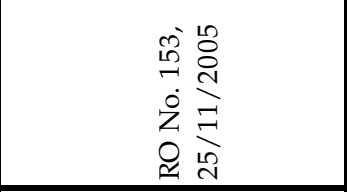 & 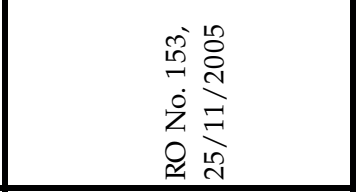 & 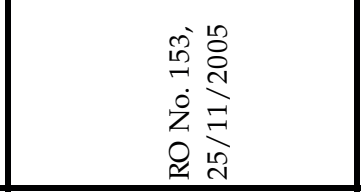 & 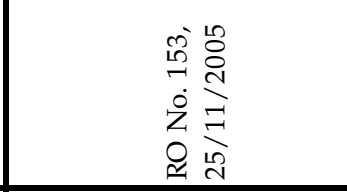 \\
\hline 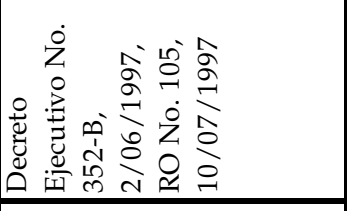 & 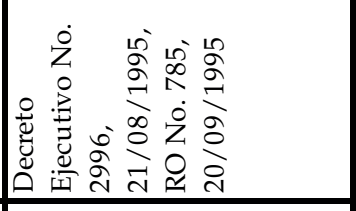 & 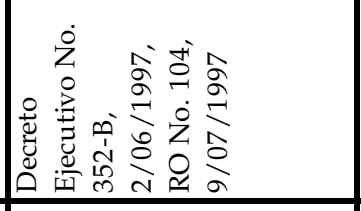 & 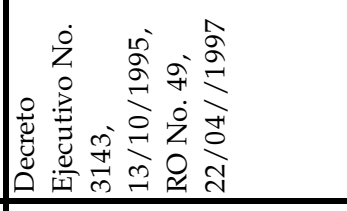 \\
\hline 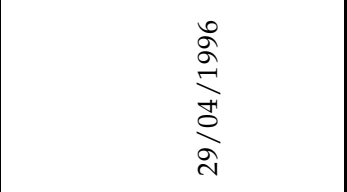 & 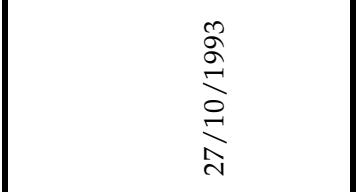 & 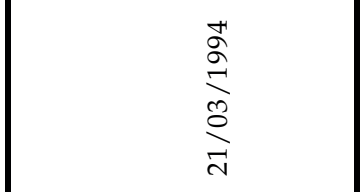 & 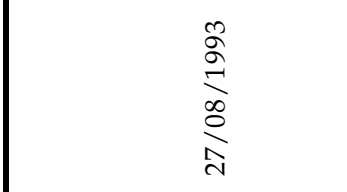 \\
\hline 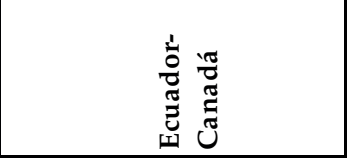 & 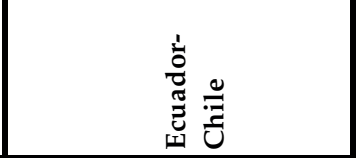 & 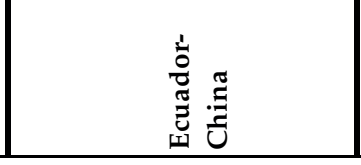 & 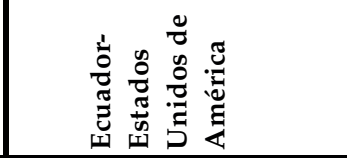 \\
\hline
\end{tabular}




\begin{tabular}{|c|c|c|c|}
\hline 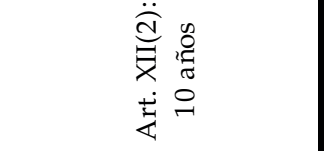 & 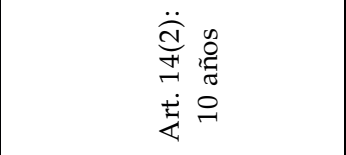 & 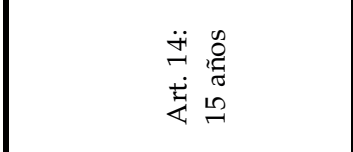 & 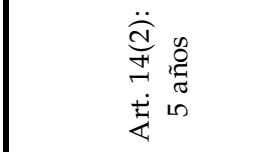 \\
\hline 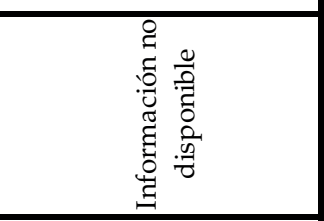 & 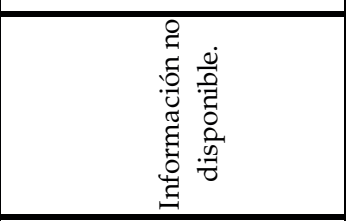 & 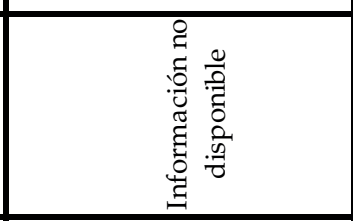 & 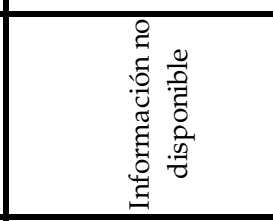 \\
\hline 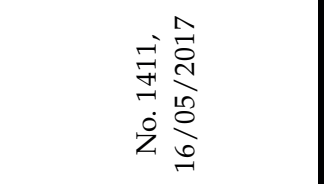 & 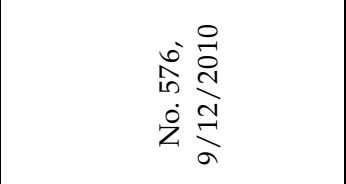 & 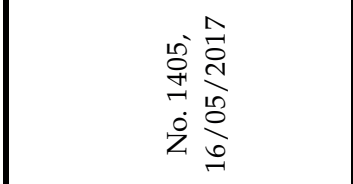 & 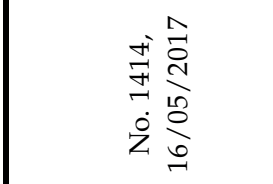 \\
\hline 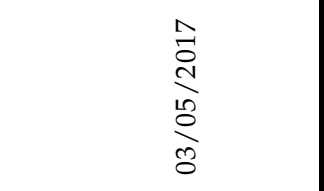 & 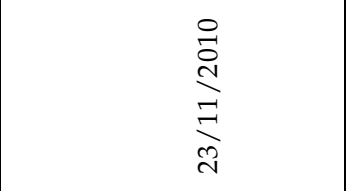 & 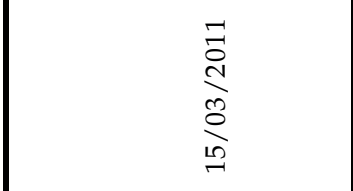 & 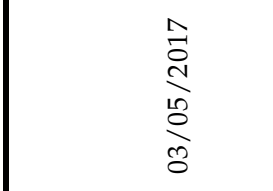 \\
\hline$\underset{\substack{0 \\
\stackrel{0}{0}}}{\stackrel{0}{0}}$ & $\begin{array}{l}\stackrel{0}{0} \\
\stackrel{2}{2} \\
\stackrel{0}{1} \\
\stackrel{\infty}{\infty} \\
-1\end{array}$ & 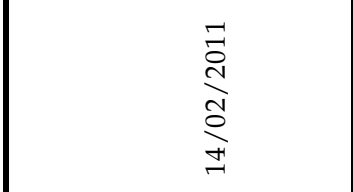 & 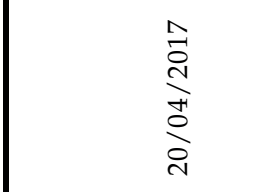 \\
\hline 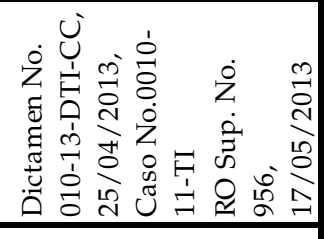 & 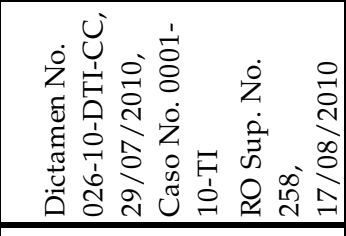 & 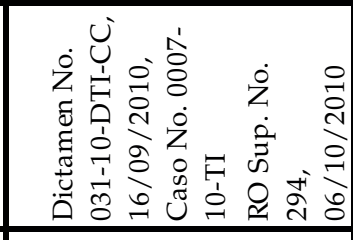 & 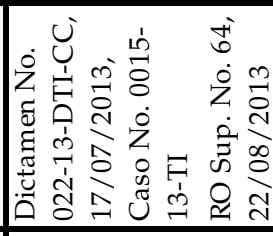 \\
\hline 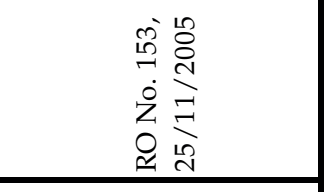 & 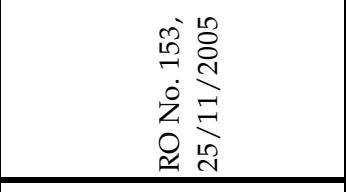 & 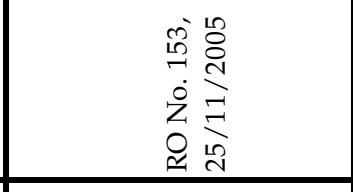 & 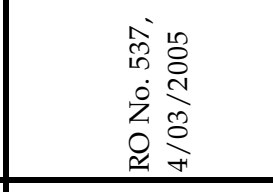 \\
\hline 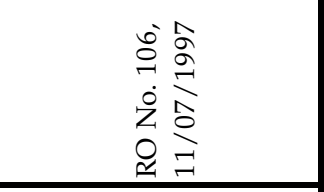 & 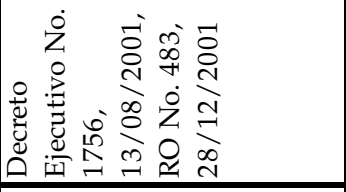 & 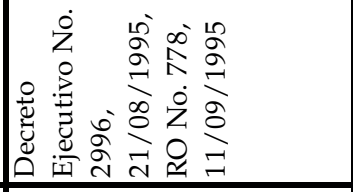 & 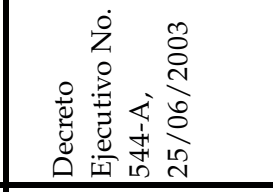 \\
\hline $\begin{array}{l}\stackrel{0}{\circ} \\
\stackrel{2}{2} \\
\frac{2}{2} \\
\frac{2}{2}\end{array}$ & 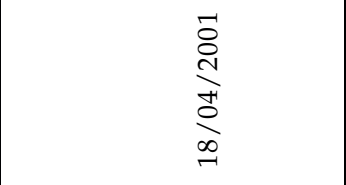 & $\begin{array}{l}\stackrel{+}{\sigma} \\
\stackrel{2}{a} \\
\frac{\partial}{2}\end{array}$ & 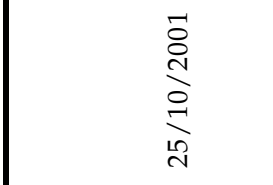 \\
\hline 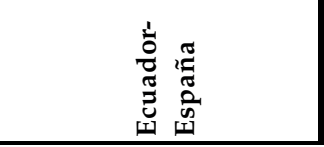 & 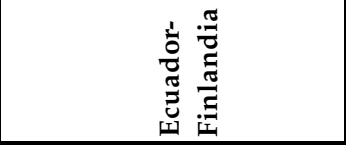 & 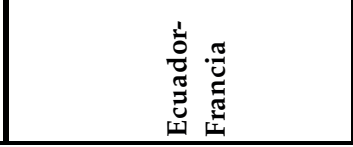 & 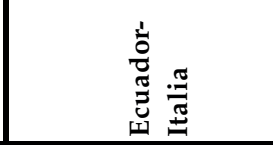 \\
\hline
\end{tabular}


El trato justo y equitativo en los tratados de protección recíproca de inversiones ecuatorianos

\begin{tabular}{|c|c|c|c|}
\hline 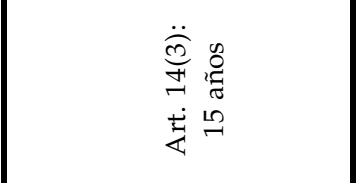 & 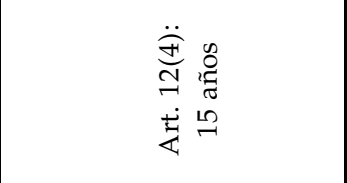 & 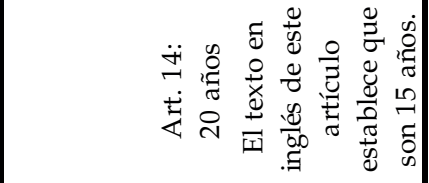 & 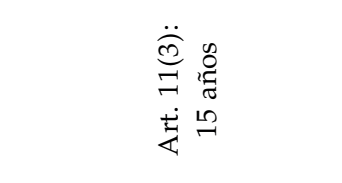 \\
\hline 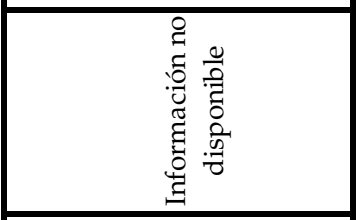 & 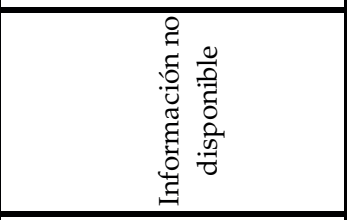 & 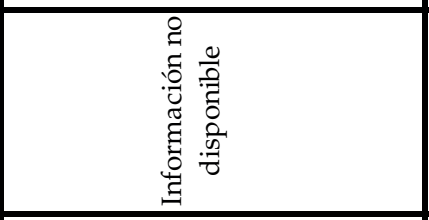 & 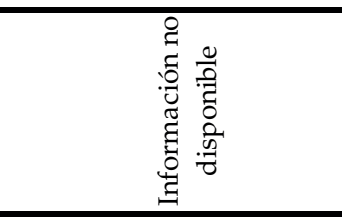 \\
\hline 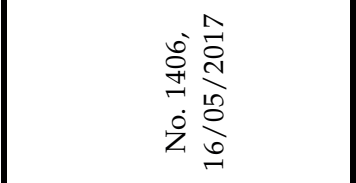 & 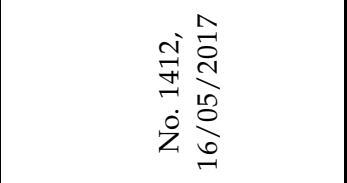 & 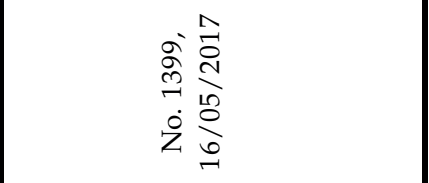 & 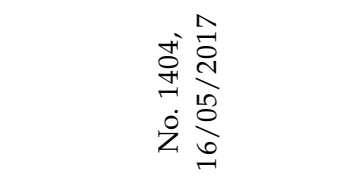 \\
\hline 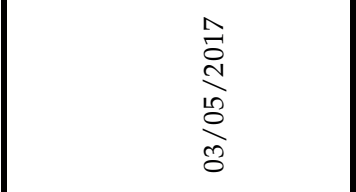 & 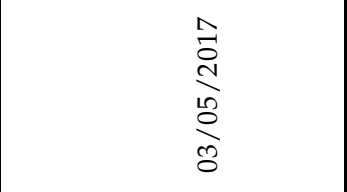 & 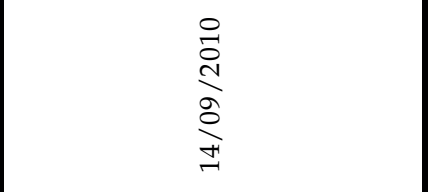 & 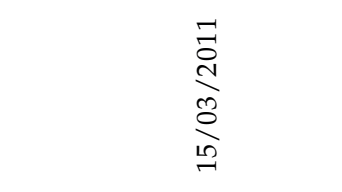 \\
\hline 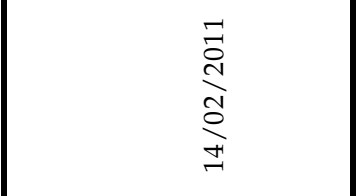 & 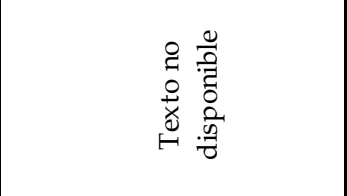 & 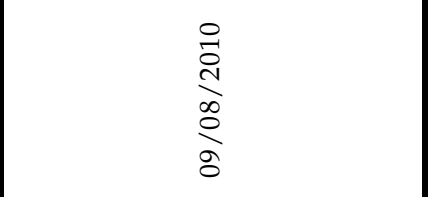 & 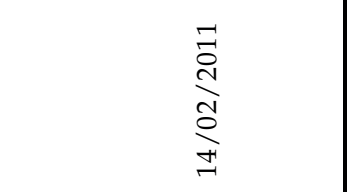 \\
\hline 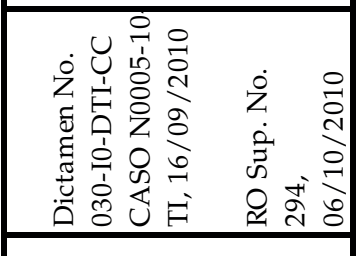 & 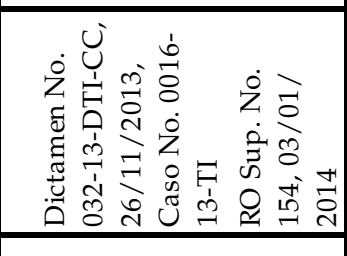 & 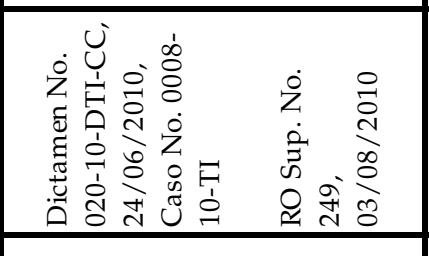 & 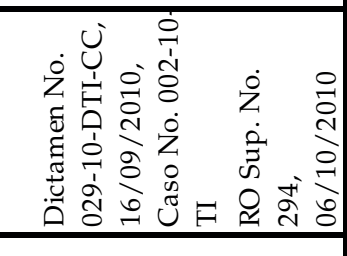 \\
\hline 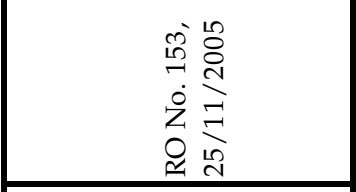 & 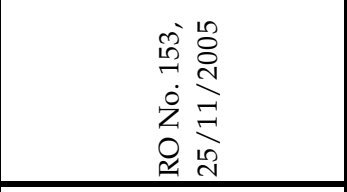 & 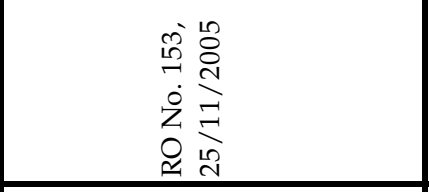 & 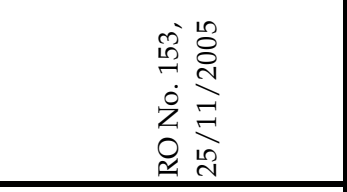 \\
\hline 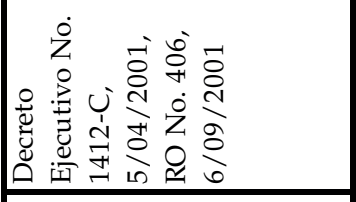 & 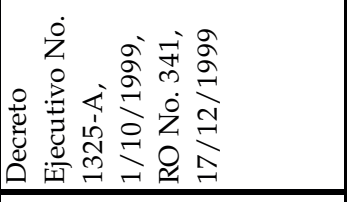 & 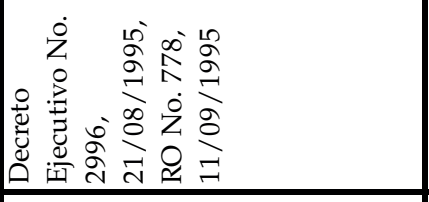 & 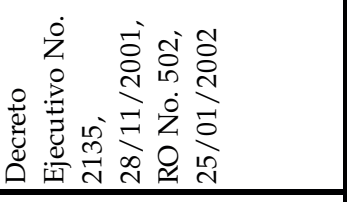 \\
\hline 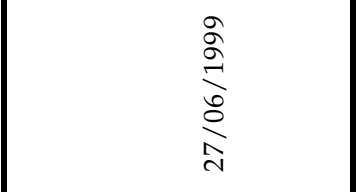 & 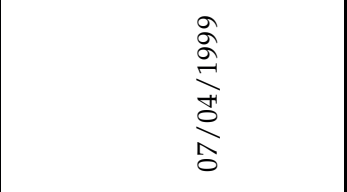 & 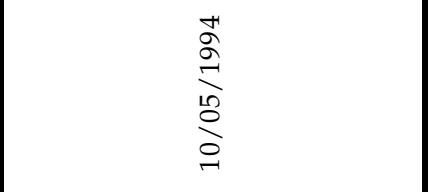 & 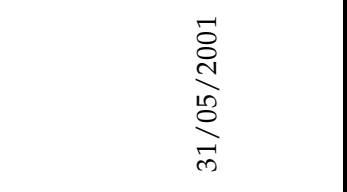 \\
\hline 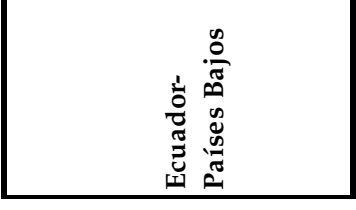 & 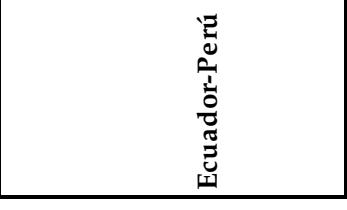 & 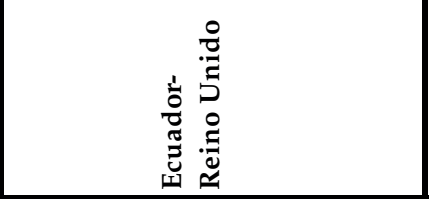 & 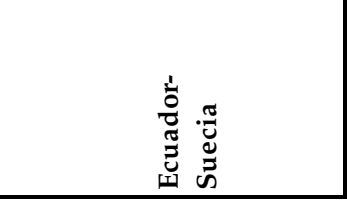 \\
\hline
\end{tabular}


Camilo Muriel Bedoya

\begin{tabular}{|c|c|}
\hline 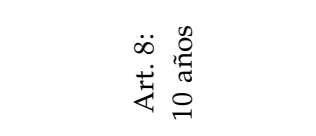 & 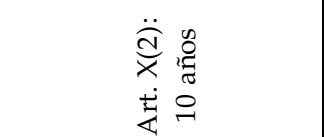 \\
\hline 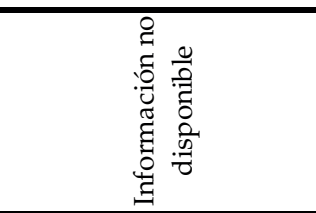 & 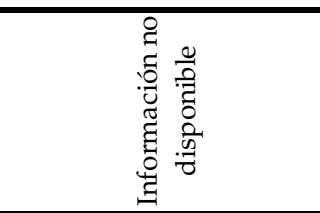 \\
\hline 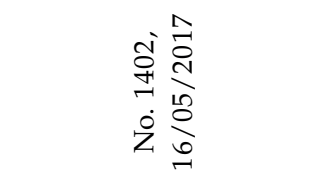 & 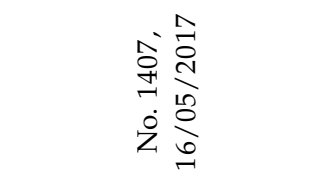 \\
\hline 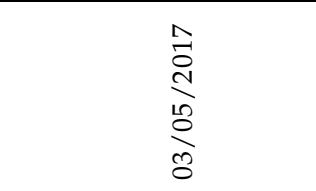 & 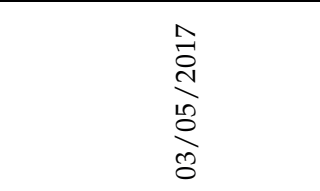 \\
\hline 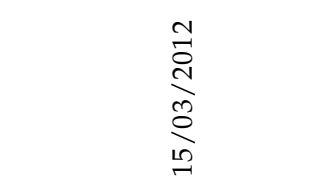 & 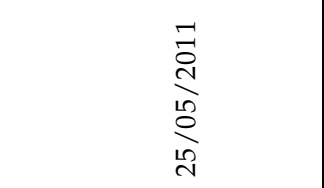 \\
\hline 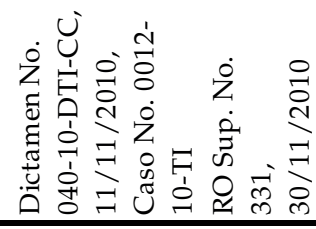 & 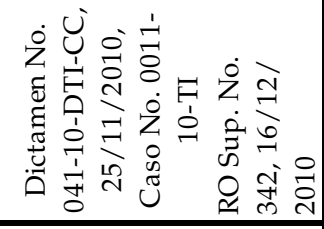 \\
\hline 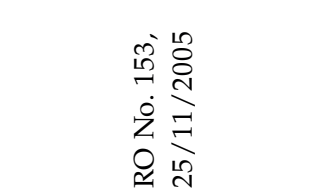 & 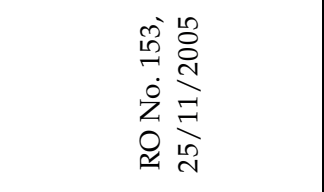 \\
\hline 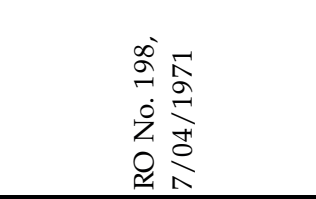 & 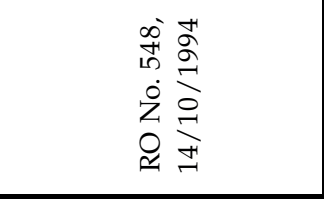 \\
\hline 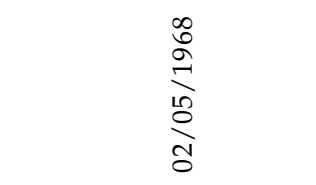 & 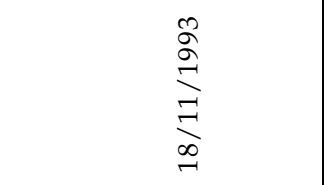 \\
\hline 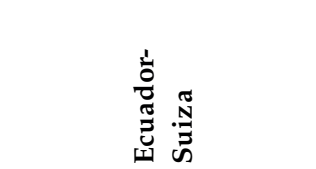 & 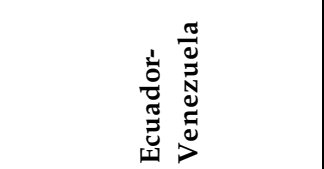 \\
\hline
\end{tabular}

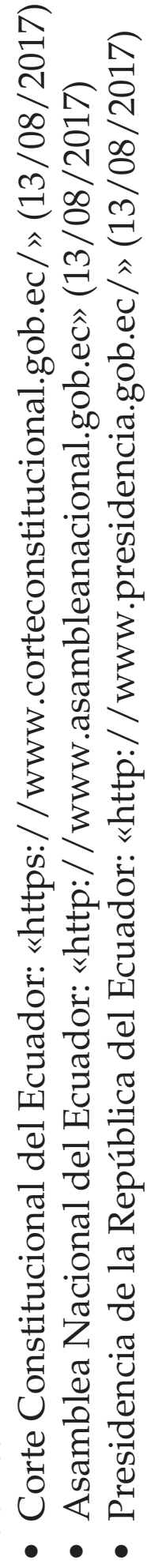

